\title{
Many ways to make darker flies: Intra- and interspecific variation in Drosophila body pigmentation components
}

\author{
Elvira Lafuente $^{1}$ (D) | Filipa Alves ${ }^{1}$ (D) | Jessica G. King ${ }^{1}$ (D) | Carolina M. Peralta ${ }^{1}$ (D) | \\ Patrícia Beldade ${ }^{1,2}$ (D)
}

${ }^{1}$ Instituto Gulbenkian de Ciência, Oeiras, Portugal

${ }^{2}$ CE3C: Centre for Ecology, Evolution, and Environmental Changes, Faculty of Sciences, University of Lisbon, Lisbon, Portugal

\section{Correspondence}

Elvira Lafuente, Department of Aquatic Ecology, Swiss Federal Institute of Aquatic Science and Technology, Dübendorf, Switzerland.

Email: elafuentemaz@gmail.com

Patrícia Beldade, CE3C: Centre for Ecology, Evolution, and Environmental Changes, Faculty of Sciences, University of Lisbon, Lisbon, Portugal.

Email: pbeldade@fc.ul.pt

\section{Present address}

Elvira Lafuente, Swiss Federal Institute of Aquatic Science and Technology, Department of Aquatic Ecology, Dübendorf, Switzerland

Jessica G. King, Institute of Evolutionary Biology, School of Biological Sciences, University of Edinburgh, Edinburgh, UK Carolina M. Peralta, Max Planck Institute for Evolutionary Biology, Plön, Germany

\section{Funding information}

Financial support for this work was provided by the Portuguese science funding agency, Fundação para a Ciência e Tecnologia, FCT: PhD fellowship to E.L. (SFRH/ $\mathrm{BD} / 52171 / 2013)$, and research grants to P.B. (PTDC/BIA-EVF/0017/2014 and PTDC/ BEX-BID/5340/2014).

\begin{abstract}
Body pigmentation is an evolutionarily diversified and ecologically relevant trait with substantial variation within and between species, and important roles in animal survival and reproduction. Insect pigmentation, in particular, provides some of the most compelling examples of adaptive evolution, including its ecological significance and genetic bases. Pigmentation includes multiple aspects of color and color pattern that may vary more or less independently, and can be under different selective pressures. We decompose Drosophila thorax and abdominal pigmentation, a valuable eco-evodevo model, into distinct measurable traits related to color and color pattern. We investigate intra- and interspecific variation for those traits and assess its different sources. For each body part, we measured overall darkness, as well as four other pigmentation properties distinguishing between background color and color of the darker pattern elements that decorate each body part. By focusing on two standard D. melanogaster laboratory populations, we show that pigmentation components vary and covary in distinct manners depending on sex, genetic background, and temperature during development. Studying three natural populations of $D$. melanogaster along a latitudinal cline and five other Drosophila species, we then show that evolution of lighter or darker bodies can be achieved by changing distinct component traits. Our results paint a much more complex picture of body pigmentation variation than previous studies could uncover, including patterns of sexual dimorphism, thermal plasticity, and interspecific diversity. These findings underscore the value of detailed quantitative phenotyping and analysis of different sources of variation for a better understanding of phenotypic variation and diversification, and the ecological pressures and genetic mechanisms underlying them.
\end{abstract}

\section{KEYWORDS}

decomposing phenotypes, developmental plasticity, genetic and environmental variance, quantitative phenotyping, thermal plasticity

This is an open access article under the terms of the Creative Commons Attribution License, which permits use, distribution and reproduction in any medium, provided the original work is properly cited.

(c) 2021 The Authors. Ecology and Evolution published by John Wiley \& Sons Ltd. 


\section{1 | INTRODUCTION}

Diversity in body coloration provides some of the most compelling examples of adaptive evolution. Insect coloration, in particular, includes text book cases such as industrial melanism (e.g., Cook \& Saccheri, 2013; van't Hof et al., 2011), mimicry (e.g., Mallet \& Joron, 1999; Nadeau, 2016), and clinal variation (e.g., Bastide et al., 2014; Endler et al., 2016; Telonis-Scott et al., 2011; Wittkopp et al., 2011). Studies in different species have illustrated the ecological significance of variation in body pigmentation, including visual communication between individuals of the same (e.g., mate attraction and mate choice; e.g., Guillermo-Ferreira et al., 2014; Wiernasz, 1995) or of different species (e.g., predator avoidance via camouflage or aposematism; e.g., van Bergen \& Beldade, 2019; Futahashi \& Fujiwara, 2008; Reichstein et al., 1968), as well as thermoregulation (e.g., Rajpurohit et al., 2008; Sibilia et al., 2018). Moreover, insect pigmentation is tightly associated with various other traits that are closely related to fitness (see Mckinnon \& Pierotti, 2010; Wittkopp \& Beldade, 2009). The diversity of insect pigmentation across species, populations, sexes, and individuals of the same sex has been the focus of many eco-evo-devo studies, providing key insight into the genetic basis of phenotypic variation (e.g., Futahashi \& Fujiwara, 2008; Massey \& Wittkopp, 2016; Miyagi et al., 2015; Orteu \& Jiggins, 2020; Pool \& Aquadro, 2007; Zhang et al., 2017) and exploring important phenomena such as developmental plasticity (e.g., Monteiro et al., 2015; Shearer et al., 2016; Solensky \& Larkin, 2003), the origin of novelty (e.g., Shirai et al., 2012; Vargas-Lowman et al., 2019), and evolutionary constraints (e.g., Allen et al., 2008; Beldade, Brakefield, et al., 2002; Beldade, Koops, et al., 2002).

Variation in body pigmentation can arise from differences in color and/or in the spatial arrangement of colors into specific patterns. These two aspects are believed to rely on largely distinct classes of genes involved in pigmentation development: those encoding the enzymes responsible for pigment synthesis, and those encoding the transcription factors regulating the expression of those enzymes at the appropriate time and location (see True, 2003; Wittkopp \& Beldade, 2009; Wittkopp et al., 2003). Changes in genes associated with each of these steps can result in changes in pigmentation between individuals and between body parts (e.g., Wittkopp et al., 2002). In this respect, body pigmentation can be thought of as a multidimensional trait, made up of several components representing aspects of actual color and of color pattern, which might vary between body parts and develop and evolve more or less independently. This has been explored in studies focusing on specific color pattern elements, including on butterfly wings (reviews in Beldade \& Peralta, 2017; Monteiro, 2015; Nijhout, 2001), as well as on fly wings and abdomens (e.g., Jeong et al., 2006; Werner et al., 2010). Yet, rarely do studies of body pigmentation variation combine quantitative analysis of multiple color and color pattern traits.

Studies of Drosophila body and wing pigmentation have provided very valuable insight about the genetic and environmental bases of variation between species, populations of the same species, and individuals of the same population (e.g., Gibert et al., 2007; Hollocher et al., 2000; Massey \& Wittkopp, 2016; Pool \& Aquadro, 2007; Wittkopp et al., 2003). These studies characterized effects of environmental factors, such as nutrition (e.g., Shakhmantsir et al., 2014) and temperature (e.g., David et al., 1990), as well as allelic variants of both subtle (e.g., Bastide et al., 2013) and large phenotypic effect (e.g., Carbone et al., 2005). Variation in Drosophila pigmentation has been associated with clinal and seasonal variation in desiccation resistance, thermoregulation, and UV protection (e.g., Matute \& Harris, 2013; Parkash et al., 2014; Rajpurohit et al., 2008) and shown to correlate with other traits, such as reproductive success, behavior, and immunity (e.g., Dombeck \& Jaenike, 2004; Massey et al., 2019; Takahashi, 2013). While studies of Drosophila pigmentation have included focus on different body parts (e.g., trident on thorax, e.g., David et al., 1985; melanic patches on wings, e.g., True et al., 1999; dark bands of abdominal segments, e.g., Dembeck et al., 2015), these studies typically analyze single and often qualitative properties of pigmentation (but see, e.g., Saleh Ziabari \& Shingleton, 2017). Indeed, the detail in quantitative phenotyping of Drosophila pigmentation does not match the sophistication of the analysis of its genetic and developmental bases. This is not unique to Drosophila pigmentation; the need for more attention to be given to phenotyping has been called for repeatedly (Deans et al., 2015; Gerlai, 2002; Houle et al., 2010; Kühl \& Burghardt, 2013; Laughlin \& Messier, 2015).

Here, we provide a detailed analysis of patterns and sources of intra- and interspecific variation in body pigmentation in Drosophila, considering aspects of both color and color pattern. For that, we quantify five traits encompassing aspects of color and color pattern of abdomen and thorax pigmentation in Drosophila adults. We investigate how each of these pigmentation components and the associations between them differ between genotypes and developmental temperatures, within and across species. We show that different pigmentation components can vary rather independently and that fly bodies can be made lighter or darker by changing distinct pigmentation components. We discuss our results in the context of the potential for evolutionary diversification of pigmentation.

\section{2 | MATERIAL AND METHODS}

\section{1 | Fly stocks and experimental design}

In this study, we used a total of 23 Drosophila fly stocks: two D. melanogaster laboratory strains CantonS (CanS) and OregonR (OreR), five different isogenic lines of $D$. melanogaster from each of three geographical locations (i.e., Finland, Austria, and Spain), two strains of D. simulans (D.sim A and D.sim B), one stock of D. malerkotliana, one stock of $D$. repleta, one stock of $D$. mojavensis baja, and one stock of D. mojavensis mojavensis. D. melanogaster strains (CanS and OreR) and Drosophila species D. simulans, D. malerkotliana, D. repleta, D. mojavensis baja, and D. mojavensis mojavensis were obtained from C. Mirth's laboratory. D. melanogaster populations from Finland (Akaa; 61.1, 23.52; collected in July 2015), Austria (Mauternbach; 48.38, 
15.57; collected in July 2016), and Spain (Tomelloso; 39.16, 3.02; collected in September 2015) were obtained from E. Sucena's laboratory and collected by members of the European Drosophila Population Genomics Consortium (DrosEu; http://droseu.net). From the species used in this study, D. melanogaster, D. simulans, and D. malerkotliana belong to the melanogaster group, which originally inhabited tropical climates, though they have become cosmopolitan species. In contrast, $D$. mojavensis and $D$. repleta belong to the repleta group, which inhabits desert climates. All stocks were maintained in molasses food (45 g molasses, $75 \mathrm{~g}$ sugar, $70 \mathrm{~g}$ cornmeal, $20 \mathrm{~g}$ yeast extract, $10 \mathrm{~g}$ agar, $1,100 \mathrm{ml}$ water, and $25 \mathrm{ml}$ of Nipagin 10\%). All stocks were kept at $25^{\circ} \mathrm{C}, 12: 12$-hr light-dark cycles. For the experiments, we performed overnight egg-laying from 20 females of each stock in vials with ad libitum molasses food. Eggs were then placed at either $17^{\circ} \mathrm{C}$ or $28^{\circ} \mathrm{C}$ throughout development. We controlled the population density by keeping between 20 and 40 eggs per vial.

For the experiment of the windows of sensitivity for pigmentation, we exposed developing flies to $17^{\circ} \mathrm{C}$ or $28^{\circ} \mathrm{C}$ during one window of development while they were kept at $23^{\circ} \mathrm{C}$ for the remaining stages. We tested four different treatments at $17^{\circ} \mathrm{C}$ and at $28^{\circ} \mathrm{C}: \mathrm{T}$ (flies always kept at constant temperature), L (late larval development; staging done by using traqueal and mouth hook morphology), $p$ (only early pupal period; from white pupa to the onset of eye pigmentation), $P$ (only late pupal period; from the onset of eye pigmentation until adult eclosion).

\section{2 | Phenotyping pigmentation components}

Adult flies (8-10 days after eclosion) were placed in 2-ml microcentrifuge tubes and frozen in liquid nitrogen. The tubes were shaken immediately after submersion in liquid nitrogen to remove wings, legs, and bristles. Headless bodies of flies were then mounted on
3\% agarose in Petri dishes, dorsal side up, and covered with water to avoid specular reflection of light upon imaging. Images containing 10-20 flies were collected with a LeicaDMLB2 stereoscope and a Nikon E400 camera under controlled conditions of illumination and white-balance adjustment. Images were later processed with a set of custom-made interactive Mathematica notebooks (Wolfram Research, Inc., Mathematica, version 10.2, Champaign, IL, 2015) to extract pigmentation measurements. For this purpose, two transects were defined on each fly, one in the thorax and one in the abdomen, using morphological landmarks (as shown in Figure 1). To minimize image noise, for each pixel position along the transect line we calculated the mean RGB (red, green, blue) values of the closest five pixels located on a small perpendicular line centered on the transect. For abdominal transects, when necessary, we removed the sections corresponding to the membranous tissue that occasionally is visible between abdominal segments. The few transects that were drawn over debris particles were excluded from the analysis, as pigmentation measurements could not be accurately extracted.

The sequence of averaged RGB pixel values corresponding to each transect was then used to define each of the five pigmentation components as follows. For each pixel, we calculated a normalized darkness value as Dmax-Dbk, where Dmax is the largest possible Euclidean distance between two colors in the RGB color space (in this case Dmax $=\sqrt{3}$ ), and Dbk is the distance of the pixel's color coordinates to the color black $(R=0, G=0, B=0)$. Overall darkness (Odk) was calculated as the sum of the normalized darkness values for each pixel divided by the number of pixels in the transect. Taking the sequence of normalized darkness values along a transect, we estimated its two enveloping lines (blue and green lines in Figure 1a) by calculating the baselines of the original and negated values using the Statistics-sensitive Non-linear Iterative Peak-clipping (SNIP) algorithm (Ryan et al., 1988). The median line of this envelope (red line in Figure 1a) was then used to separate the transect pixels into two
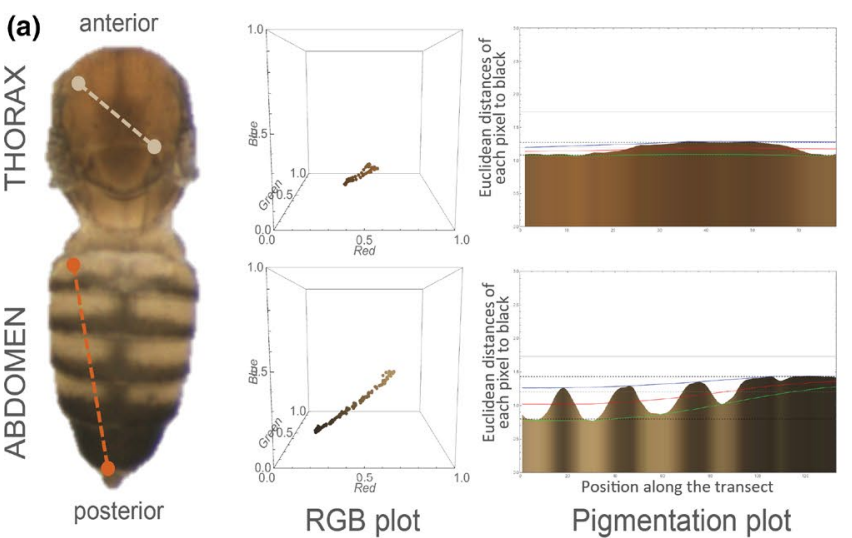

(b)

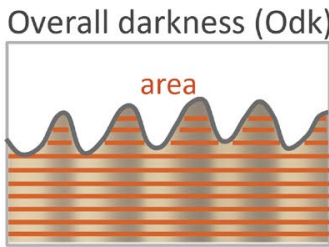

Pattern (Pat)

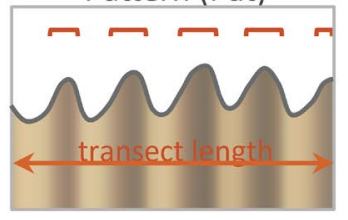

Range (Ran)

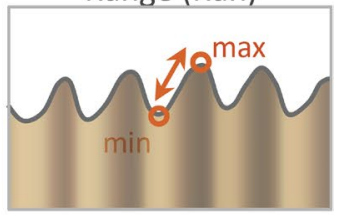

Color (Cbk and Cpa)

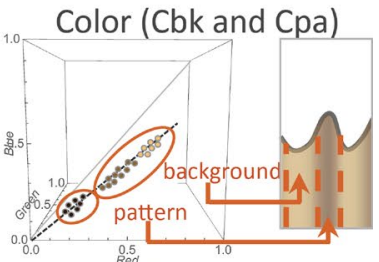

FIGURE 1 Quantitative analysis of body pigmentation. (a) Thorax and abdomen from female of $D$. melanogaster OreR reared at $17^{\circ} \mathrm{C}$ showing the body landmarks used to draw the transects. For each pixel in the transect, we extracted RGB values that are represented in the RGB plots (cubes on the right side of each transect). By calculating the distance between each of those pixels to the black, we converted the RGB vectors into two-dimensional information and represented the distance of each pixel ( $y$-axis) from the anterior to the posterior extremes of the transect ( $x$-axis) (plots on the right side). (b) Diagram showing the different pigmentation traits. Overall darkness (Odk), difference between lightest and darkest color (Ran), relative length of dark "ornamental" pattern (Pat), color of background (Cbk), and color of pattern "ornamental" elements (Cpa) (see Materials and Methods) 
clusters, where the pixels above or below this line correspond, respectively, to the pattern element (trident in the thorax and darker bands in the abdomen) or to the background. Pattern (Pat) was calculated as the proportion of pixels corresponding to the pattern element relative to the transect length. Color of the pattern element (Cpa) is the angle defined in the RGB color space between the best-fitted line going through the color coordinates of the pixels in the transect that correspond to the pattern element (trident and/or darker bands) in the transect and the gray vector (the black to white diagonal in the RGB color space). Similarly, color of the background (Cbk) was calculated as the angle between the best-fitted line that goes through the color coordinates of the background pixels in the transect and the gray vector. Pixels corresponding to pattern element and/or background were defined by grouping all RGB values in the transect into two clusters each containing $95 \%$ of the light or dark pixels, respectively. Range (Ran) was calculated as the Euclidean distance between the median values of the 20 darkest and the 20 lightest pixels along the transects. The colors represented in Figure 2 correspond to the mean $\mathrm{R}$, mean $\mathrm{G}$, and mean $\mathrm{B}$ values for each strain/species, sex, and temperature, which were calculated from $\mathrm{Cpa}$ for color of pattern elements and from Cbk for color of the background, respectively.

\section{3 | Statistical analyses}

All analyses were conducted in R v 3.6.2 (R Core Team, 2019), using the following R packages: tidyr (Wickham \& Henry, 2020) to arrange datasets, ggplot2 (Wickham, 2009) to produce plots, Ime4 (Bates et al., 2015) and ImerTest (Kuznetsova et al., 2017) to perform linear mixed-effects models, Hmisc (Harrell et al., 2020) and corrplot (Taiyun \& Viliam, 2017) to compute correlation matrices, and emmeans (Lenth et al., 2018) to perform post hoc pairwise comparisons between groups. The statistical models described below are given in package-specific R syntax (shown in italics).

Multivariate multiple regression was performed for the data on D. melanogaster laboratory populations to test for the effect of strain, sex, temperature (fixed explanatory variables), and interaction terms in all pigmentation traits by combining all traits using the cbind function (model Im(cbind(Odk, Pat, Ran, Cbk, Cpa) Strain * Sex * Temperat ure)). A similar analysis was performed for the data on $D$. melanogaster clinal populations testing for the fixed effects and interactions of location, genotype (i.e., isogenic line; nested within location), and temperature (model Im(cbind(Odk, Pat, Ran, Cbk, Cpa) Location * Genotype * Temperature), and for the Drosophila species, testing for the fixed effects and interactions of species, strain (nested within species), sex, and temperature (model Im(cbind(Odk, Pat, Ran, Cbk, Cpa) $\sim$ Species * Species/Strain * Sex * Temperature)), where Strain corresponds to the different genetic backgrounds analyzed in $D$. melanogaster (CanS and OreR) and in D. simulans (D. sim A and D. sim B).

Linear mixed effect models were then used to test for the (fixed) effects of different explanatory fixed variables (strains, genotypes or species, sex, and temperature) and their interactions on each of the pigmentation traits (noted as trait in the model notations below). Replicate, which corresponds to each independent cohort of flies (for any given species/genotype/temperature), was included as random effect in the models (denoted as (1|Replicate) in the R syntax below). (a)

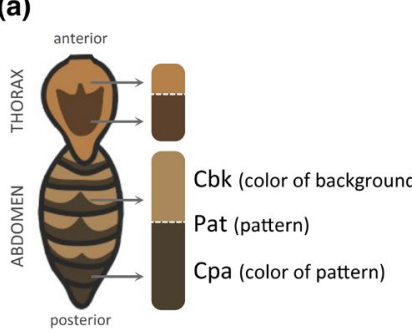

(d)

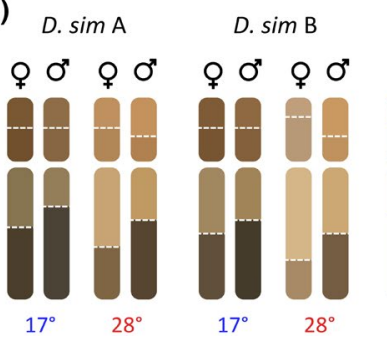

(b)

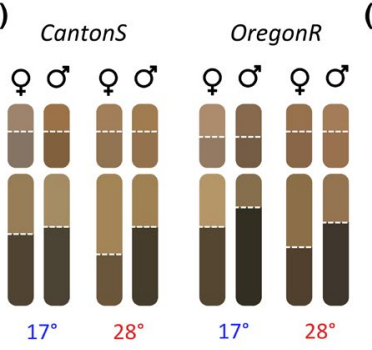

D. $m a l$

D. moj baj

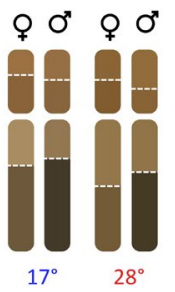

(c)

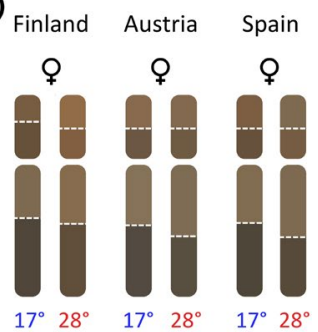

FIGURE 2 Intra- and interspecific variation in Drosophila pigmentation. (a) Illustration of a D. melanogaster headless body showing the dorsal side of the thorax and abdomen and the scheme we used to represent pigmentation traits for thorax (top rounded rectangle) and abdomen (bottom rounded rectangle). For each of these, the horizontal dashed line separates the color of pattern element (Cpa) and the color of background (Cbk). These are shown in mean color (RGB values) for same-group individuals, and the height of the dashed line represents the proportion of the transect that is occupied by pattern versus background (Pat). See more details in Figure 1. (b) Pigmentation schemes per strain, sex, and temperature in D. melanogaster laboratory populations. (c) Pigmentation schemes in D. melanogaster clinal populations, showing mean values from the five genotypes (i.e., isogenic lines) per location. (d) Pigmentation schemes in five Drosophila species with one genetic background per species except $D$. simulans where two genetic backgrounds $(D$. sim $A$ and $D$. sim $B)$ were studied 

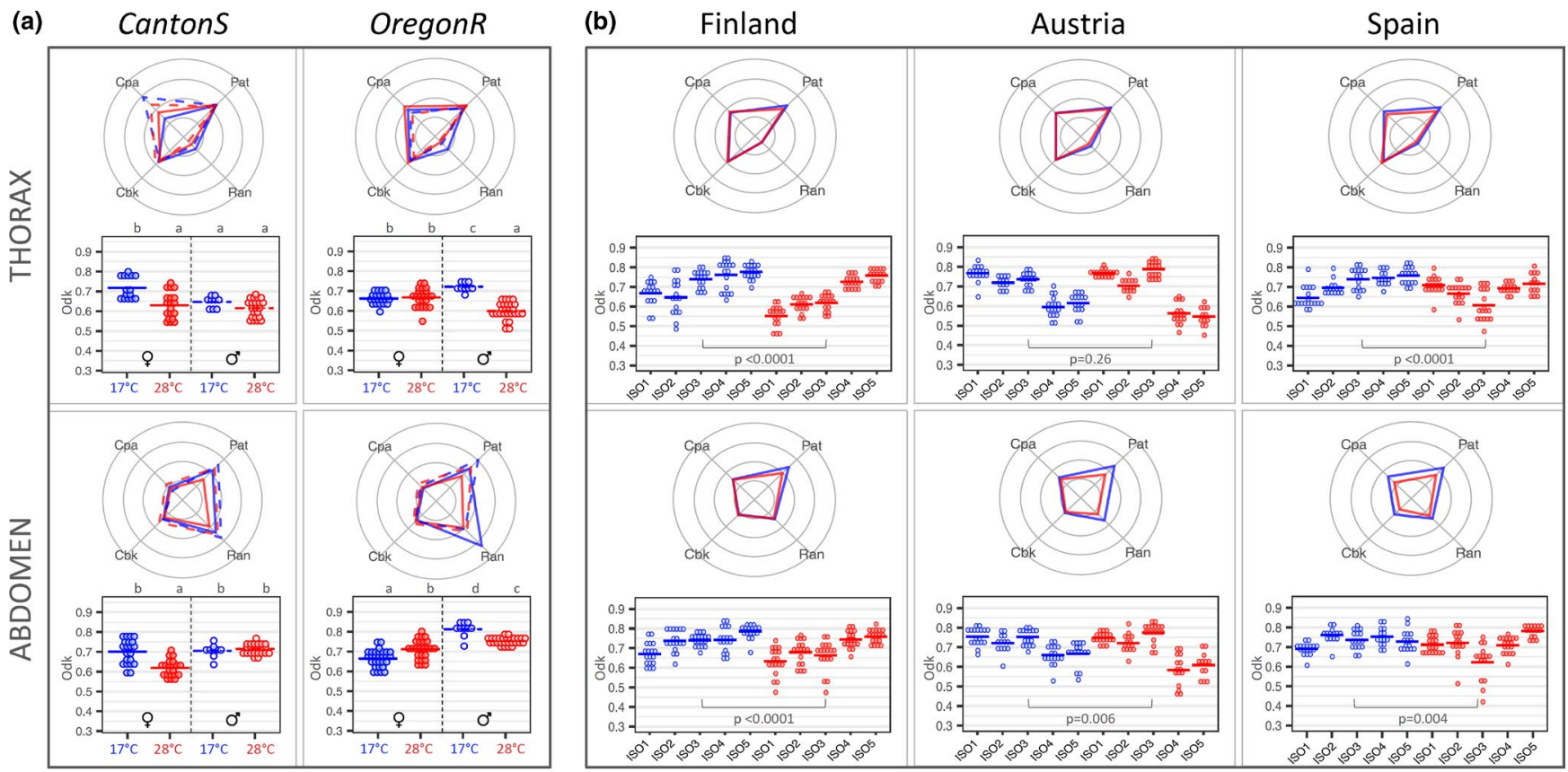

(c)
D. $\operatorname{sim} A$

D. $\operatorname{sim} B$

D. $\mathrm{mal}$

D. moj baj

D. moj moj

D. rep
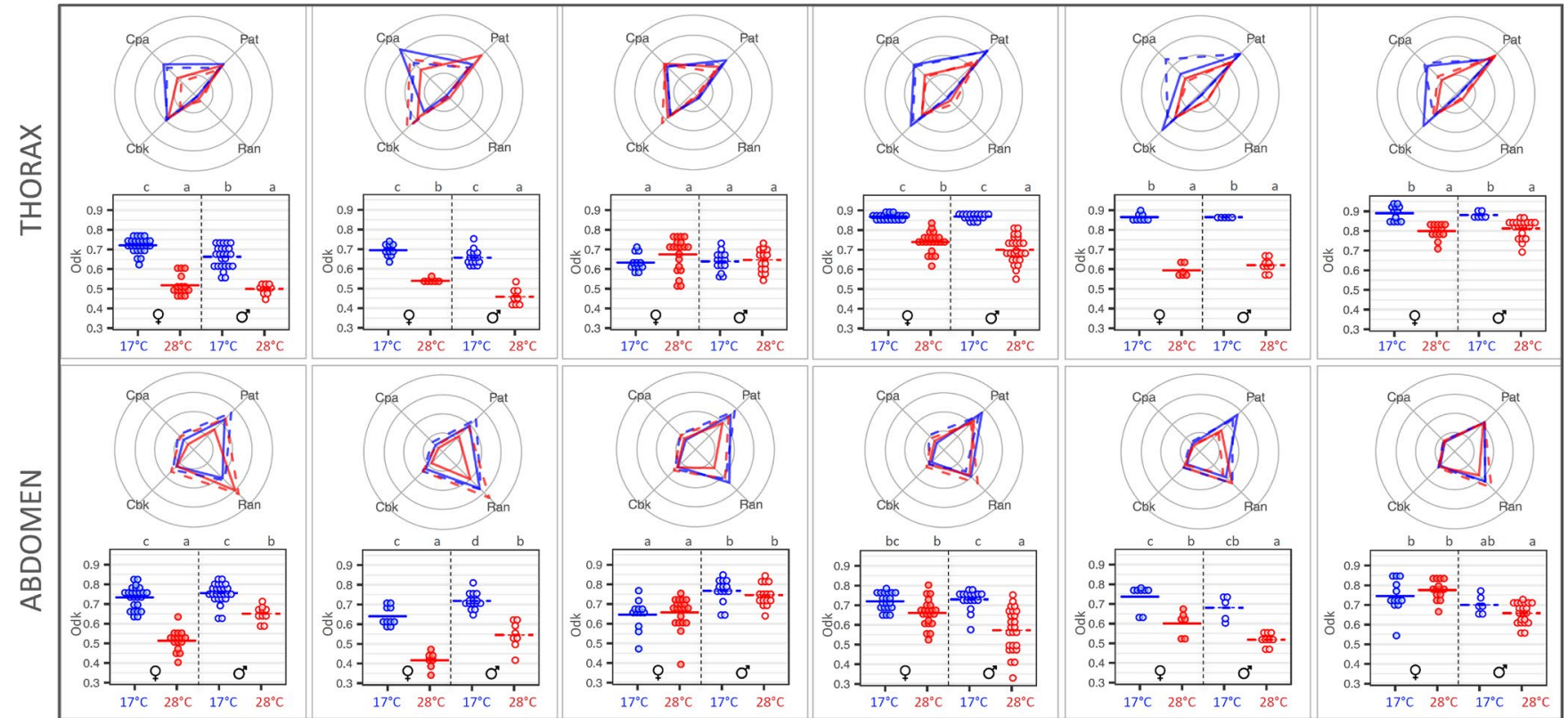

웅

FIGURE 3 Quantitative phenotyping of Drosophila pigmentation component traits. For each population, temperature, sex, and body part, radar plots represent variation for Pat, Ran, $\mathrm{Cpa}$, and Cbk (means; dot plots in Figure S1) and dot plots represent variation for Odk (individual data points and means). Females/males are shown as solid/dashed lines (radar plots) or closed/empty circles (dot plots), and flies reared at $17^{\circ} \mathrm{C} / 28^{\circ} \mathrm{C}$ are shown in blue/red. (a) D. melanogaster laboratory populations. Results of statistical test for the effect of sex, temperature, and their interaction on each of the traits are shown in Table A2. Letters in dot plots indicate results of post hoc pairwise comparisons between groups: different letters when significantly different ( $p$-value $<.05$ for Tukey's honest significance test). (b) $D$. melanogaster clinal populations. For each geographical population, we phenotyped females from five genotypes (i.e., isogenic lines). Results for the effect of location, genotype, and temperature (and interactions) on the different pigmentation traits are in Table A4. Results of the statistical test ( $p$-value) for the effect of temperature on each of the traits are shown in plots. (c) Drosophila species. Results of the statistical test for effect of sex, temperature, and their interaction are in Table A5. Letters in dot plots indicate results of post hoc pairwise comparisons between groups: different letters when significantly different ( $p$-value $<.05$ for Tukey's honest significance test) 
For D. melanogaster laboratory strains: model Imer(Trait $\sim$ Sex ${ }^{*}$ Tempe rature + (1|Replicate)). The same model was used for all Drosophila species, except for $D$. simulans, where we also included the factor Strain which corresponds to the different genetic backgrounds studied in this species (D. sim A and D. sim B) (model: Imer(Trait Strain * Sex * Te mperature + (1|Replicate))). For the clinal populations: model: Imer(Tra it $\sim$ Location * Location/Genotype * Temperature + (1|Replicate)). For all the aforementioned mixed models, we used Satterthwaite's method (via ANOVA function in ImerTest package; Kuznetsova et al., 2017) for approximating degrees of freedom and estimating $F$-statistics and $p$ values. For the data on the sensitive stages of development, we used linear effect models to test for the effect and interaction of strain and thermal regime (model: $\operatorname{Im}$ (Trait $\sim$ Strain * Regime)).

We used post hoc pairwise comparisons (Tukey's honest significant differences) to identify differences between strains, sexes, temperatures, and/or thermal regimes. Pearson's correlations were used to check correlations between traits and across temperatures. We used Holm $p$-value adjustment method to correct for multiple comparisons (Holm, 1979).

\section{3 | RESULTS}

To investigate patterns and sources of variation in Drosophila body pigmentation, we quantified five pigmentation traits that include aspects of color and color pattern (see Figure 1 and Materials and Methods). We focused on the dorsal surface of thoraxes and abdomens, characterized for having different types of darker "pattern elements" on a lighter "background" color: a trident at the center of the thorax and bands on each segment of the abdomen. For each body part, we extracted color information along transects running antero-posteriorly on each body part and quantified a series of pigmentation traits (Figures 1 and 2a): overall darkness (Odk), the relative length of transect occupied by the darker "ornamental" pattern (Pat), the actual color of both background (Cbk) and "ornamental" pattern elements (Cpa), and the distance in RGB space between the darkest and the lightest color that corresponds to the range of color variation (Ran). We investigated how these pigmentation components vary and covary between sexes and between rearing temperatures in $D$. melanogaster representing standard laboratory strains, and natural populations from different geographical locations, as well as in five additional Drosophila species. For each dataset (D. melanogaster laboratory strains, D. melanogaster clinal populations, and Drosophila species), the multivariate multiple regression analyses showed that pigmentation differed significantly between strains/genotypes/species, sexes, and temperatures, with effects that depended on body part (Table A1).

\section{1 | Variation in body pigmentation in D. melanogaster laboratory populations}

We reared flies from two common laboratory genetic backgrounds of D. melanogaster, Oregon R (OreR) and Canton S (CanS), at either $17^{\circ} \mathrm{C}$ or $28^{\circ} \mathrm{C}$ to assess thermal plasticity and sexual dimorphism in our pigmentation traits (Figures 2 and 3, Figure S1a, Table A2). We found that flies reared at lower temperature were generally darker than those reared at higher temperature and that males were generally darker than females (Figures 2b and 3a, Figure S1a), as has been previously described in D. melanogaster (e.g., Gibert et al., 2009). Yet, we also found differences between strains and body parts in the extent and sometimes the direction of both thermal plasticity and sexual dimorphism for our pigmentation traits (Figures $2 \mathrm{~b}$ and 3a, Figure S1a, Table A2), as well as for the correlations between them (Figure 4a).

For overall darkness (Odk; dot plots in Figure 3a), flies reared at $17^{\circ} \mathrm{C}$ were generally darker than those from $28^{\circ} \mathrm{C}$, with the exception of CanS males (where differences were not significant in either body part) and OreR females (where abdomens were darker in flies from $28^{\circ} \mathrm{C}$ ). The abdomens were lighter in females relative to males (except for CanS from $17^{\circ} \mathrm{C}$ ), but the thoraxes were lighter in males relative to females (except for CanS from $28^{\circ} \mathrm{C}$ and OreR from $17^{\circ} \mathrm{C}$ ). We also observed differences between sexes and temperatures for the other pigmentation traits (Pat, Ran, Cbk, and Cpa; radar plots in Figure 3a; dot plots in Figure S1a, Table A2), which depended on body part. Sexual dimorphism and plasticity were lowest for traits reflecting actual color (i.e., Cbk and Cpa) (Figure S1a). While for the thorax, the most striking differences were seen in Ran (for females between temperatures), for the abdomen they were seen for Pat (distinguishing females from $28^{\circ} \mathrm{C}$ from others) and Ran (extreme for OreR females) (Figure S1a). Variation was only loosely correlated between traits, with few significant correlations, which differed between genetic backgrounds, sexes, and rearing temperatures (Figure 4a). Overall, correlations between traits were weaker across body parts relative to within body parts and in males relative to females.

For those pigmentation traits found to be thermally plastic (i.e., significant differences between individuals reared at different temperatures; cf. Figure S1a, Table A2), we investigated which stages of development were thermally responsive. To do so, we compared phenotypes between individuals (specifically, female abdomens) differing in temperature only for specific developmental time windows (Figure $4 \mathrm{~b}$, Table A3). We tested nine thermal regimes (or treatments), including three with constant temperatures (whole development at $17^{\circ} \mathrm{C}, 23^{\circ} \mathrm{C}$, or $28^{\circ} \mathrm{C}, \mathrm{T} 17, \mathrm{~T} 23$, and $\mathrm{T} 28$ treatments, respectively) and six where most of the development took place at $23^{\circ} \mathrm{C}$ and only one specific stage (either late larval, early pupal, or late pupal) took place at $17^{\circ} \mathrm{C}$ or at $28^{\circ} \mathrm{C}$. Differences between constant temperatures (T17, T23, and T28 treatments) revealed thermal reaction norms, i.e., the representation of phenotype as a function of temperature (see Schlichting \& Pigliucci, 1998), of different shapes for different pigmentation components: T23 phenotype intermediate between T17 and T28 (Ran in OreR; Figure 4b), equal to one of the extreme temperatures (Pat; Figure $4 b$ ), or more extreme than both T17 and T28 (Odk; Figure 4b). The period when exposure to a different temperature significantly affected phenotype also differed between traits and genetic backgrounds (Figure 4b), showing that traits and genetic backgrounds differ not only in the extent of thermal plasticity, but also in what developmental stage is thermally responsive. 
(a)

$17^{\circ}$

O THORAX ABDOMEN

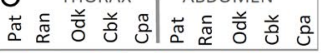

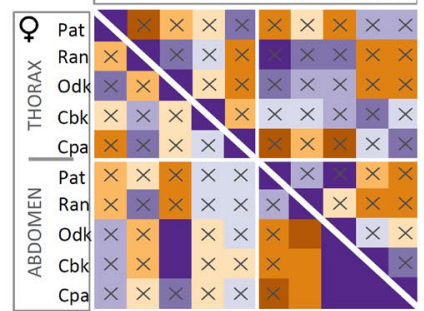

Cantons

$28^{\circ}$

O" THORAX ABDOMEN

范空

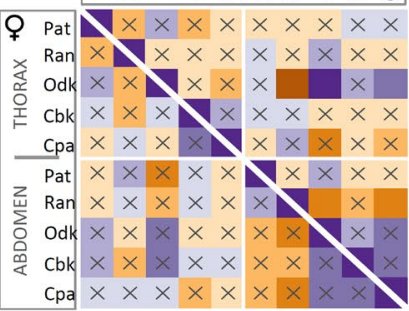

OregonR

$17^{\circ}$

O" THORAX ABDOMEN

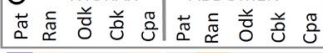

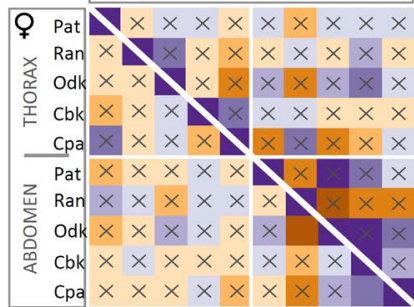

$28^{\circ}$

O" THORAX ABDOMEN

落突

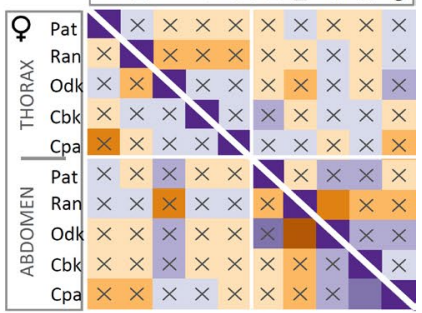

$\mathrm{O}^{\mathrm{N}}$ Magnitude of correlation (b)

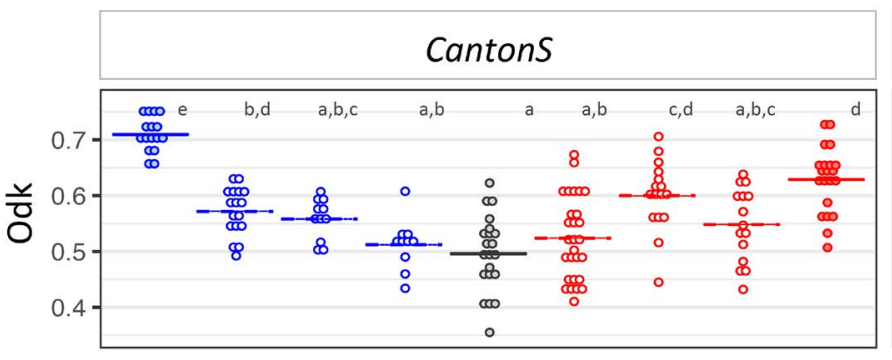

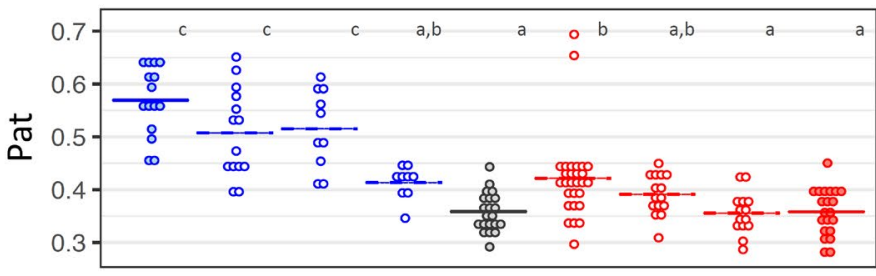

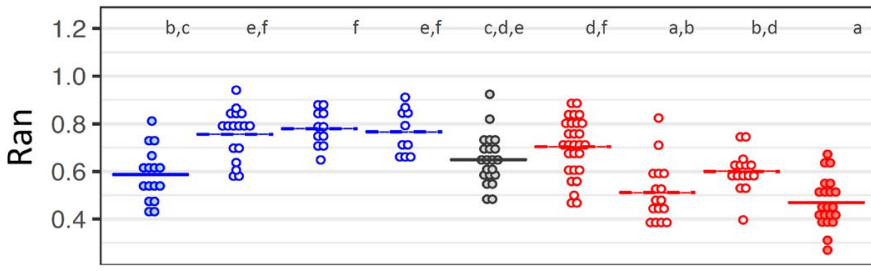

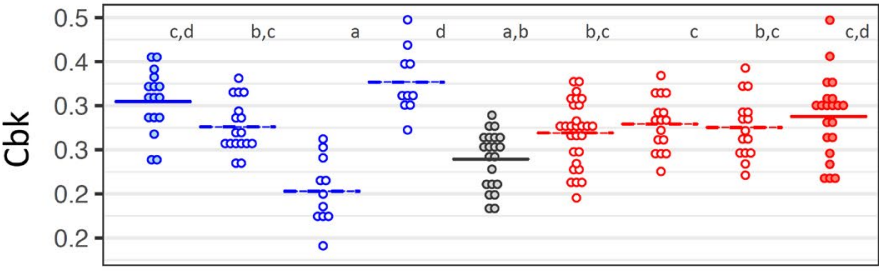

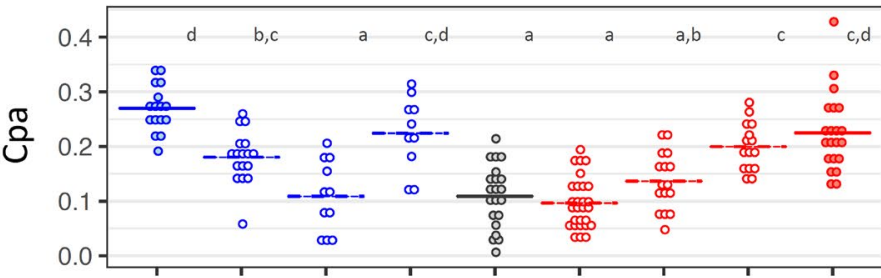

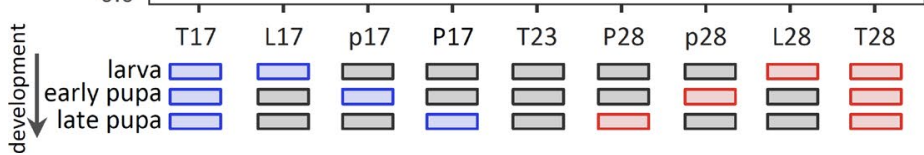
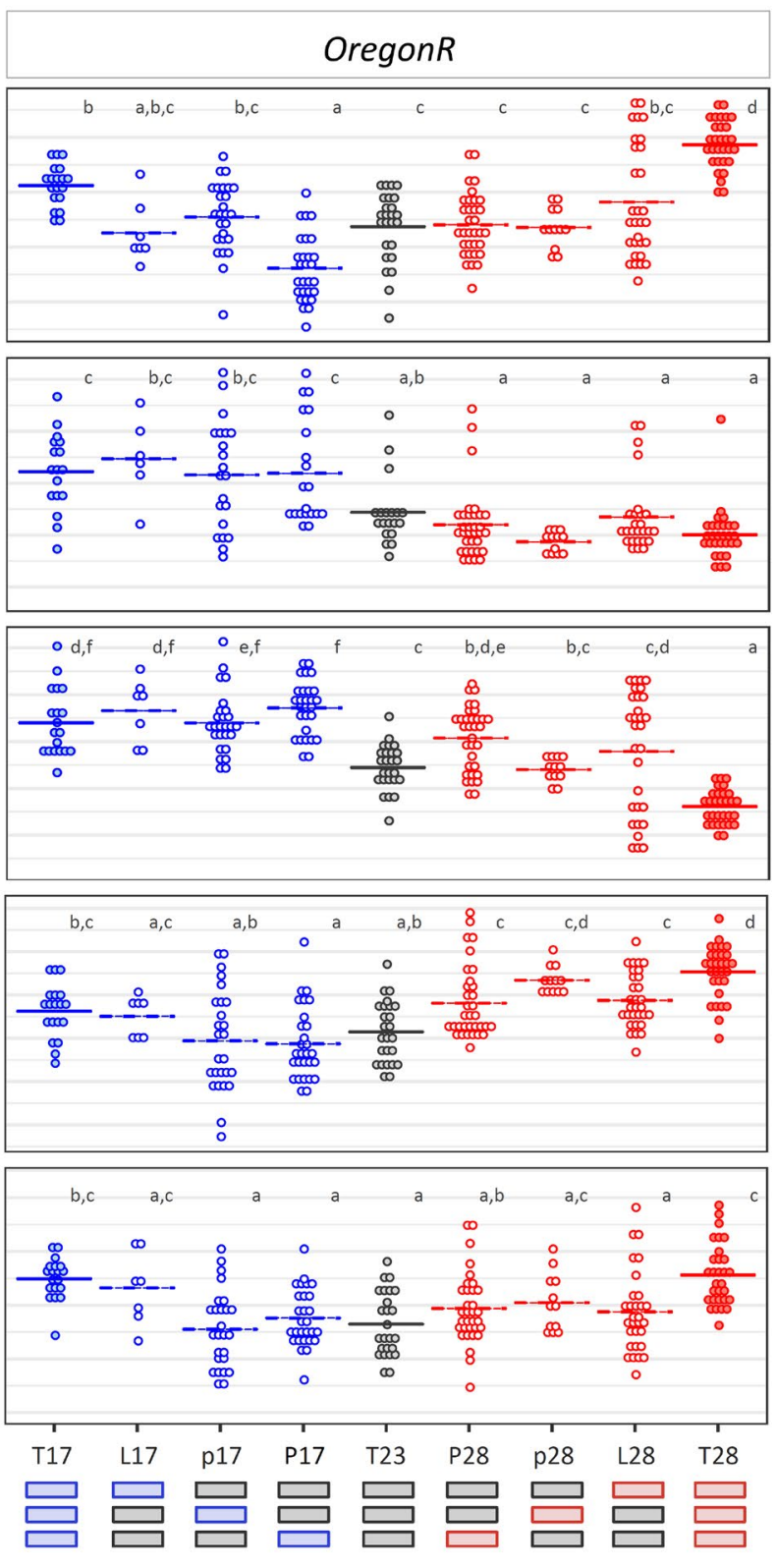
FIGURE 4 Covariation and thermal sensitivity of D. melanogaster pigmentation components. (a) Heat map of Pearson's correlation coefficients for all pigmentation traits in abdomens and thoraxes of CanS (left panels) and OreR (right panels) of flies reared at $17^{\circ} \mathrm{C}$ or $28^{\circ} \mathrm{C}$. For each matrix, females are in the left corner and males in the right. Positive correlations are shown in purple and negative correlations in orange. Correlations not statistically significant (after Holm $p$-value adjustment method for multiple comparisons) are indicated with a cross. (b) Pigmentation traits ( $y$-axis) in females of two D. melanogaster genetic backgrounds (CanS and OreR) exposed to each of the temperature regimes during development ( $x$-axis). The thermal regimes codes and corresponding stages that were exposed to either $17^{\circ} \mathrm{C}$ or $28^{\circ} \mathrm{C}$ (instead of the basal temperature of $23^{\circ} \mathrm{C}$ ) were as follows: $T$ (constant temperature), $L$ (late larval development), $p$ (early pupal period), and $P$ (late pupal period). In each graph, dots represent phenotypes of single individual females, and the horizontal bar is the mean of those values. The results of the test for differences between strains and thermal regimes on the different plastic traits are shown in Table A3. Letters indicate results of post hoc pairwise comparisons between groups: different letters when significantly different ( $p$-value $<.05$ for Tukey's honest significance test)

\section{2 | Body pigmentation differences in D. melanogaster natural populations and Drosophila species}

We explored patterns of variation in pigmentation components in wild-caught populations sampled along a latitudinal cline in Europe: Finland, Austria, and Spain (samples from the DrosEU Consortium; http://droseu.net/). We quantified pigmentation traits in females from five genotypes (isofemale lines) established from each of the three geographical locations, reared at either $17^{\circ} \mathrm{C}$ or $28^{\circ} \mathrm{C}$. The analysis for each pigmentation component revealed differences between traits in their response to the various explanatory variables and their interactions (Figures 2c and 3b, Table A4). Geographical populations differed in overall darkness (Odk; dot plots in Figure $3 \mathrm{~b}$ ) and in color (both $\mathrm{Cbk}$ and $\mathrm{Cpa}$ ) for the abdomen, but not the thorax (Figure 5, Figure S2, Table A4). Most pigmentation traits (except thorax color; $\mathrm{Cpa}$ and $\mathrm{Cbk}$ ) were thermally plastic, with darker flies for development at $17^{\circ} \mathrm{C}$ relative to $28^{\circ} \mathrm{C}$ (Figures $2 \mathrm{c}$ and $3 \mathrm{~b}$, Figure S2). The northern- and southern-most populations (i.e., Finland and Spain, respectively) did not necessarily show the most extreme phenotypes, neither in terms of overall darkness nor in the extent of plasticity therein (Figure 3b, Figure 5). We also found significant differences between isofemale genotypes (and their plasticity) within each geographical location (Figure 3b, Table A4).

Finally, we assessed pigmentation variation in flies from five additional Drosophila species (two genetic backgrounds for D. simulans and one genetic background for all other species or subspecies: $D$. malerkotliana, D. repleta, D. mojavensis baja, D. mojavensis mojavensis) reared at either $17^{\circ} \mathrm{C}$ or $28^{\circ} \mathrm{C}$ (Figures $2 \mathrm{~d}$ and $3 \mathrm{C}$ ). We found differences between species in extent and direction of sexual dimorphism and of thermal plasticity for the different pigmentation traits (Figures $2 \mathrm{~d}$ and 3c, Figure S1b, Table A5). For instance, for Odk (dot plots in Figure 3c),
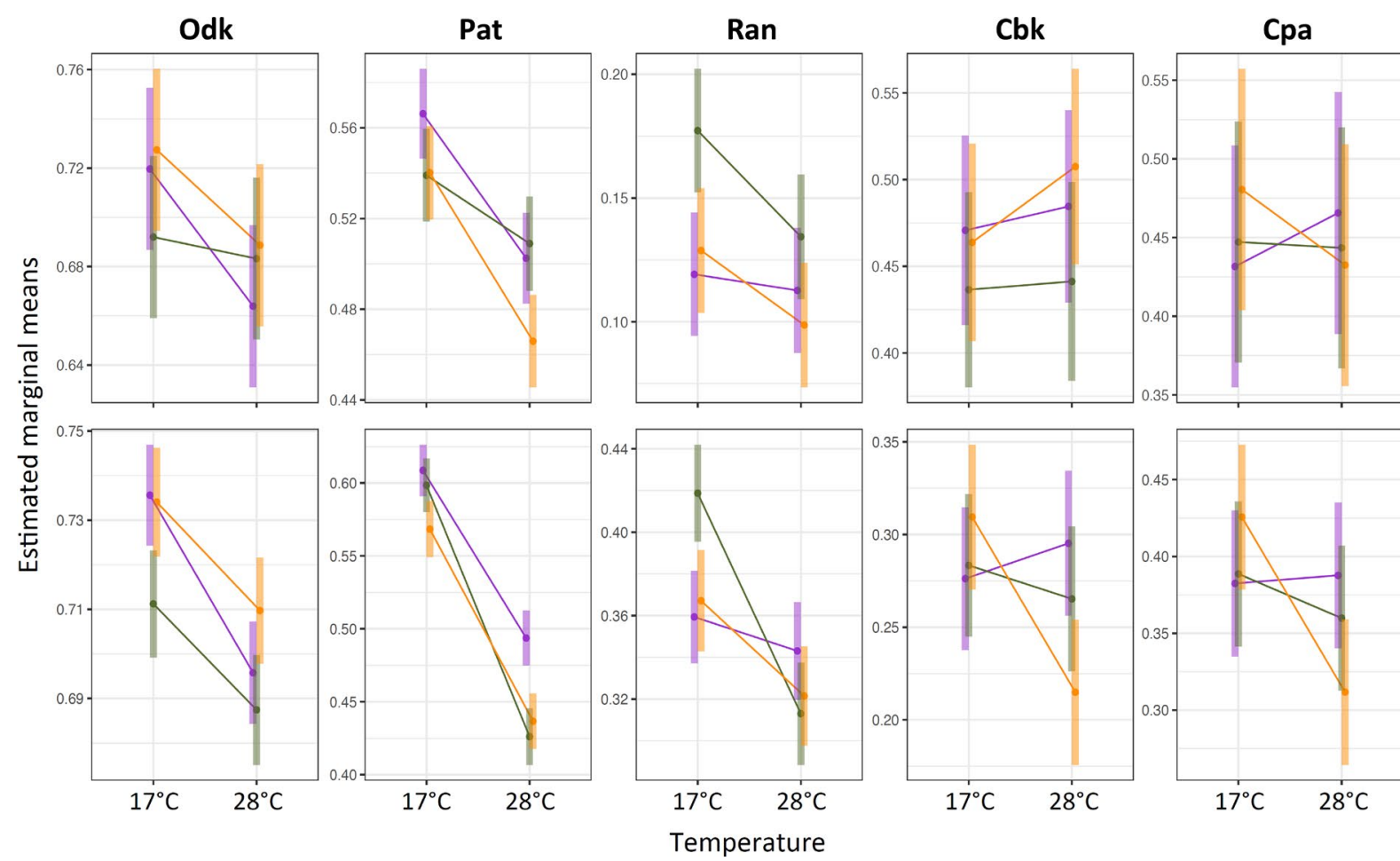

Population

Finland Austria Spain

FIGURE 5 Effects of temperature on pigmentation traits in D. melanogaster European populations. Interaction plot showing the estimated marginal means and confidence intervals of all pigmentation traits based on fitted model Imer(Trait Location * Location/ Genotype * Temperature + (1|Replicate)) 
D. malerkotliana showed no differences between temperatures and clear differences between sexes, while $D$. simulans had very high thermal plasticity but reduced sexual dimorphism (no differences between females and males reared at $17^{\circ} \mathrm{C}$ ). For the other pigmentation traits (radar plots in Figure 3c and dot plots in Figure S1b), larger differences between sexes and/or temperatures were observed for Pat and/or Ran and less for actual colors (Cpa and Cbk).

\section{DISCUSSION}

We decomposed Drosophila body pigmentation into different quantitative traits, including overall darkness (Odk), and traits reflecting properties of color and color pattern (Pat, Ran, Cbk, and Cpa) of both thoraxes and abdomens (Figure 1). We showed differences in trait values, as well as in the extent and direction of thermal plasticity and of sexual dimorphism, for laboratory and natural populations of D. melanogaster and several Drosophila species (Figures 2, 3, and 5). Different traits, corresponding to different properties of body pigmentation, behaved in a largely independent manner, which was also reflected in low levels of correlations between traits and in differences in the period of development during which traits are thermally responsive (Figure 4).

Drosophila pigmentation has been the focus of various studies exploring its ecology, development, and evolution (e.g., Gibert et al., 2017; Kopp et al., 2000; Matute \& Harris, 2013; Shearer et al., 2016; Williams et al., 2008). This has provided great insight about the genetic basis and ecological significance of variation, across temporally (e.g., seasonal variation) and geographically (e.g., clinal variation) distinct populations (e.g., Parkash et al., n.d.; Hollocher et al., 2000b; Rajpurohit et al., 2008), as well as across species (Hollocher et al., 2000a, 2000b). Many of those studies focused on specific pigmentation elements in particular species and often used qualitative assessments of pigmentation variation or presence/absence of specific pattern elements (e.g., David et al., 2002; Hollocher et al., 2000). In D. melanogaster, for instance, most work has focused on abdominal pigmentation and specifically on the width of the dark bands of the abdominal segments, which is sexually dimorphic (males are generally darker than females; e.g., Kopp et al., 2000) and thermally plastic (flies from lower developmental temperatures are generally darker than flies from higher developmental temperatures; e.g., David et al., 1990; Gibert et al., 2007, 2009). Our analysis, quantifying different properties, including actual color, of both abdomen and thorax pigmentation in D. melanogaster and other Drosophila species, revealed a more complex picture of variation in body pigmentation. We did not, for example, always find that males were darker than females or that flies reared at lower temperatures were darker than those from higher temperatures. Rather, we found trait specificities in how pigmentation varied between sexes and between developmental temperatures. This was true not only for overall darkness (Odk) of the abdomen, the trait that should be more similar to previous characterizations of abdominal pigmentation (e.g., David et al., 1990; Hollocher et al., 2000a), but also for other properties of body pigmentation, including actual color of background and pattern elements (i.e., abdominal bands and thoracic trident), which had not been investigated before. Moreover, we also showed that pigmentation components, as well as sexual dimorphism and thermal plasticity therein, vary greatly between species, genotypes, and body parts. The mechanisms underlying such intra- and interspecific variation in different traits, as well as the trait-specific responses to temperature, remain to be explored and might involve differences in the environmental sensitivities of the regulatory regions (e.g., enhancers) controlling pigmentation-related genes (e.g., De Castro et al., 2018).

Our results also show only weak correlations between traits, which differ between sexes and with rearing temperatures (Figure 4a). Environmental effects on trait associations have been described previously; for instance, cold temperature triggered a shift in the sign of the correlation between body size and longevity in D. melanogaster (Norry \& Loeschcke, 2002). Differing correlations between body parts (or regions within a body part) have also been identified for D. melanogaster pigmentation (e.g., Bastide et al., 2014; Gibert et al., 2000), with the extent of genetic correlations decreasing with increasing distance between body segments (Gibert et al., 2000). Ultimately, the dependency of trait associations on genetic and environmental factors has the potential to influence adaptation (e.g., Manenti et al., 2016; Marquez \& Knowles, 2007), as evolutionary change can result from both direct and correlated responses to selection (e.g., Rajpurohit \& Gibbs, 2012). Altogether, our results suggest a large degree of developmental and evolutionary independence between pigmentation components, which could facilitate the diversification of body coloration in Drosophila. This is also apparent in that we find differences between traits in the extent of thermal plasticity and sexual dimorphism (Figures 2 and 3), as well as in which period during development temperature affects adult phenotype (Figure 4b).

Studies exploring the ecological conditions driving the evolution of melanism in Drosophila have documented correlations between body pigmentation and several eco-geographic variables (e.g., latitude, altitude, temperature, humidity) (e.g., Gibert et al., 2016; Rajpurohit et al., 2008; Shearer et al., 2016). Clinal variation in pigmentation has been shown for thoracic trident (e.g., David et al., 1985; Telonis-Scott et al., 2011) and for abdominal pigmentation (e.g., Das, 2009; Pool \& Aquadro, 2007). Generally, darker phenotypes in colder environments (e.g., at high latitudes or altitudes) have been hypothesized to allow flies to better absorb solar radiation (c.f. thermal budget or thermal melanism hypothesis; Clusella-Trullas et al., 2008; Trullas et al., 2007), to increase desiccation resistance (e.g., Parkash et al., 2008), and/or to provide protection against UV radiation (e.g., Bastide et al., 2014). Plasticity, on the other hand, is expected to be greater in environments that are more variable (Lande, 2014), such as those with larger seasonal fluctuations, often occurring at higher latitudes. However, our analysis of the pigmentation patterns from $D$. melanogaster populations collected along a European latitude cline (Finland, Austria, Spain) did not always revealed darker pigmentation nor higher plasticity in the 
northern-most population (Finland). This may reflect that other environmental parameters and ecological conditions-not considered in our study-could account for the differences between populations in the pigmentation components. It is also possible that having only three populations from three latitudes may be limiting our assessment of latitudinal patterns in pigmentation and plasticity therein.

In terms of a function in thermoregulation favoring darker flies in cooler environments (David et al., 1985; Hollocher et al., 2000a; Matute \& Harris, 2013; Shearer et al., 2016; Wittkopp et al., 2011), we could expect our trait overall darkness (Odk) to be the most relevant trait. Our analyses revealed that flies can become overall darker (higher Odk) by changing actual colors of background or of ornamental elements (Cbk and Cpa, respectively) or the proportion of the abdomen/thorax length covered with the darker bands/trident (Pat). For instance, males of CanS reared at $17^{\circ} \mathrm{C}$ and $28^{\circ} \mathrm{C}$ show the same overall darkness (Odk), but differ in what pigmentation components make that up; Odk is mostly determined by color components at $17^{\circ} \mathrm{C}$ and by color pattern components at $28^{\circ} \mathrm{C}$ (i.e., $\mathrm{Cpa}$ and $\mathrm{Cbk}$ are lower, while Pat and Ran are higher at $17^{\circ} \mathrm{C}$ than at $28^{\circ} \mathrm{C}$ ). It is unclear whether these traits are mere components of the overall body darkness (Odk) or can themselves be under direct natural selection.

Variation in pigmentation between body parts, individuals, populations, and species can be caused by differences in actual color and/or in how colors are spatially organized to make up color patterns (Nijhout, 2010; Wittkopp \& Beldade, 2009). However, seldom do studies of animal pigmentation consider and quantify distinct pigmentation component traits, and the extent to which they might be differently affected by genetic and/or environmental factors, and might develop and evolve more or less independently from each other. The increased attention to studying the mechanisms underlying phenotypic variation resulted in great detail and sophistication in the characterization of its genetic underpinnings. However, the detail in describing and quantifying phenotypes has lagged behind. The lack of quantitative methods for phenotyping (see Gerlai, 2002; Houle et al., 2010) can result in an oversimplification of complex phenotypes, dismissing that those phenotypes are often made up of distinct component traits that can respond to internal and external factors in different manners (e.g., Mateus et al., 2014; Vrieling et al., 1994). We attempted to provide a better resolution of variation in Drosophila body color, a visually compelling example of adaptive evolution. Combining it with existing genetic resources and with access to natural variation can provide a deeper resolution of the patterns and processes underlying phenotypic variation, within and between species.

\section{CONFLICT OF INTEREST}

The authors declare that no conflict of interest exists. The funders had no role in study design, data collection and analysis, decision to publish, or preparation of the manuscript.

\section{AUTHOR CONTRIBUTIONS}

Elvira Lafuente: Conceptualization (equal); data curation (lead); formal analysis (lead); funding acquisition (supporting); investigation (lead); methodology (equal); project administration (equal); supervision (supporting); visualization (equal); writing-original draft (lead); writing-review \& editing (lead). Filipa Alves: Formal analysis (equal); methodology (equal); software (equal); visualization (supporting); writing-review \& editing (supporting). Jessica G. King: Formal analysis (supporting); investigation (equal); writing-review \& editing (supporting). Carolina M. Peralta: Investigation (equal); visualization (equal); writing-review \& editing (supporting). Patrícia Beldade: Conceptualization (equal); formal analysis (supporting); funding acquisition (lead); methodology (equal); project administration (lead); resources (lead); supervision (lead); visualization (equal); writingoriginal draft (supporting); writing-review \& editing (equal).

\section{DATA AVAILABILITY STATEMENT}

Data are available from Dryad Data Repository at https://doi. org/10.5061/dryad.kwh70rz3m.

\section{ORCID}

Elvira Lafuente iD https://orcid.org/0000-0002-2166-686X

Filipa Alves (D) https://orcid.org/0000-0003-0538-1685

Jessica G. King (iD https://orcid.org/0000-0003-1460-1096

Carolina M. Peralta iD https://orcid.org/0000-0002-8058-4952

Patrícia Beldade iD https://orcid.org/0000-0001-7831-979X

\section{REFERENCES}

Allen, C. E., Beldade, P., Zwaan, B. J., Brakefield, P. M., Ramos, D., \& Zwaan, B. J. (2008). Differences in the selection response of serially repeated color pattern characters: Standing variation, development, and evolution. BMC Evolutionary Biology, 8, 94. https://doi. org/10.1186/1471-2148-8-94

Bastide, H., Betancourt, A., Nolte, V., Tobler, R., Stöbe, P., Futschik, A., \& Schlötterer, C. (2013). A genome-wide, fine-scale map of natural pigmentation variation in Drosophila melanogaster. PLoS Genetics, 9, e1003534.

Bastide, H., Yassin, A., Johanning, E. J., \& Pool, J. E. (2014). Pigmentation in Drosophila melanogaster reaches its maximum in Ethiopia and correlates most strongly with ultra-violet radiation in sub-Saharan Africa. BMC Evolutionary Biology, 14, 179. https://doi.org/10.1186/ s12862-014-0179-y

Bates, D., Mächler, M., Bolker, B., \& Walker, S. (2015). Fitting linear mixed-effects models using Ime4. Journal of Statistical Software, 67, 1-48.

Beldade, P., Brakefield, P. M., \& Long, A. D. (2002). Contribution of Distal-less to quantitative variation in butterfly eyespots. Nature, 415, 315-318. https://doi.org/10.1038/415315a

Beldade, P., Koops, K., \& Brakefield, P. M. (2002). Modularity, individuality, and evo-devo in butterfly wings. Proceedings of the National Academy of Sciences of the United States of America, 99, 14262-14267.

Beldade, P., \& Peralta, C. M. (2017). Developmental and evolutionary mechanisms shaping butterfly eyespots. Current Opinion in Insect Science, 19, 22-29. https://doi.org/10.1016/j.cois.2016.10.006

Carbone, M. A., Llopart, A., deAngelis, M., Coyne, J. A., \& Mackay, T. F. C. (2005). Quantitative trait loci affecting the difference in pigmentation between Drosophila yakuba and D. santomea. Genetics, 171, 211-225.

Clusella-Trullas, S., Terblanche, J. S., Blackburn, T. M., \& Chown, S. L. (2008). Testing the thermal melanism hypothesis: A macrophysiological approach. Functional Ecology, 22, 232-238. https://doi. org/10.1111/j.1365-2435.2007.01377.x 
Cook, L. M., \& Saccheri, I. J. (2013). The peppered moth and industrial melanism: Evolution of a natural selection case study. Heredity (Edinb), 110, 207-212. https://doi.org/10.1038/hdy.2012.92

Das, A. (2009). Abdominal pigmentation in Drosophila melanogaster females from natural Indian populations. Journal of Zoological Systematics and Evolutionary Research, 33, 84-87. https://doi. org/10.1111/j.1439-0469.1995.tb00213.x

David, J. R., Capy, P., \& Gauthier, J.-P. (1990). Abdominal pigmentation and growth temperature in Drosophila melanogaster: Similarities and differences in the norms of reaction of successive segments. Journal of Evolutionary Biology, 3, 429-445. https://doi.org/10.1046/ j.1420-9101.1990.3050429.x

David, J., Capy, P., Payant, V., \& Tsakas, S. (1985). Thoracic trident pigmentation in Drosophila melanogaster: Differentiation of geographical populations. Genetics Selection Evolution, 17, 211-224. https://doi. org/10.1186/1297-9686-17-2-211

David, J. R., Gibert, P., Pétavy, G., \& Moreteau, B. (2002). Variable modes of inheritance of morphometrical traits in hybrids between Drosophila melanogaster and Drosophila simulans. Proceedings of the Royal Society B-Biological Sciences, 269, 127-135.

De Castro, S., Peronnet, F., Gilles, J.-F., Mouchel-Vielh, E., \& Gibert, J.-M. (2018). bric à brac (bab), a central player in the gene regulatory network that mediates thermal plasticity of pigmentation in Drosophila melanogaster. PLoS Genetics, 14, e1007573.

Deans, A. R., Lewis, S. E., Huala, E., Anzaldo, S. S., Ashburner, M., Balhoff, J. P., Blackburn, D. C., Blake, J. A., Burleigh, J. G., Chanet, B., Cooper, L. D., Courtot, M., Csösz, S., Cui, H., Dahdul, W., Das, S., Dececchi, T. A., Dettai, A., Diogo, R., ... Mabee, P. (2015). Finding our way through phenotypes. PLoS Biology, 13, e1002033. https://doi.org/10.1371/ journal.pbio.1002033

Dembeck, L. M., Huang, W., Magwire, M. M., Lawrence, F., Lyman, R. F., \& Mackay, T. F. C. (2015). Genetic architecture of abdominal pigmentation in Drosophila melanogaster. PLoS Genetics, 11, e1005163. https:// doi.org/10.1371/journal.pgen.1005163

Dombeck, I., \& Jaenike, J. (2004). Ecological genetics of abdominal pigmentation in Drosophila falleni: A pleiotropic link to nematode parasitism. Evolution, 58(3), 587.

Endler, L., Betancourt, A. J., Nolte, V., \& Schlötterer, C. (2016). Reconciling differences in Pool-GWAS between populations: A case study of female abdominal pigmentation in Drosophila melanogaster. Genetics, 202, 843-855.

Futahashi, R., \& Fujiwara, H. (2008). Identification of stage-specific larval camouflage associated genes in the swallowtail butterfly, Papilio xuthus. Development Genes and Evolution, 218, 491-504. https://doi. org/10.1007/s00427-008-0243-y

Gerlai, R. (2002). Phenomics: Fiction or the future? Trends in Neurosciences, 25, 506-509. https://doi.org/10.1016/S0166-2236(02)02250-6

Gibert, J.-M., Mouchel-Vielh, E., De Castro, S., \& Peronnet, F. (2016). Phenotypic plasticity through transcriptional regulation of the evolutionary hotspot gene tan in Drosophila melanogaster. PLoS Genetics, 12, e1006218. https://doi.org/10.1371/journal.pgen.1006218

Gibert, J.-M., Mouchel-Vielh, E., \& Peronnet, F. (2017). Modulation of yellow expression contributes to thermal plasticity of female abdominal pigmentation in Drosophila melanogaster. Scientific Reports, 7, 43370. https://doi.org/10.1038/srep43370

Gibert, J.-M.-M., Peronnet, F., \& Schlötterer, C. (2007). Phenotypic plasticity in Drosophila pigmentation caused by temperature sensitivity of a chromatin regulator network. PLoS Genetics, 3, 266-280. https:// doi.org/10.1371/journal.pgen.0030030

Gibert, P., Moreteau, B., \& David, J. R. (2000). Developmental constraints on an adaptive plasticity: Reaction norms of pigmentation in adult segments of Drosophila melanogaster. Evolution \& Development, 2, 249-260.

Gibert, P., Moreteau, B., \& David, J. R. (2009). Phenotypic plasticity of abdomen pigmentation in two geographic populations of Drosophila melanogaster: Male-female comparison and sexual dimorphism. Genetica, 135, 403-413. https://doi.org/10.1007/s1070 9-008-9286-2

Guillermo-Ferreira, R., Therézio, E. M., Gehlen, M. H., Bispo, P. C., \& Marletta, A. (2014). The role of wing pigmentation, UV and fluorescence as signals in a neotropical damselfly. Journal of Insect Behavior, 27, 67-80.

Harrell, F. E. J. \& Others., with contributions from C.D. and many. 2020. Hmisc: Harrell miscellaneous. R package version 4.4-2.

Hollocher, H., Hatcher, J. L., \& Dyreson, E. G. (2000a). Evolution of abdominal pigmentation differences across species in the Drosophila dunni subgroup. Evolution, 54, 2046-2056. https://doi.org/10.1111/ j.0014-3820.2000.tb01248.x

Hollocher, H., Hatcher, J. L., \& Dyreson, E. G. (2000b). Genetic and developmental analysis of abdominal pigmentation differences across species in the Drosophila dunni subgroup. Evolution (N. Y.), 54, 20572071. https://doi.org/10.1111/j.0014-3820.2000.tb01249.x

Holm, S. (1979). A simple sequentially rejective multiple test procedure. Scandinavian Journal of Statistics, 6, 65-70.

Houle, D., Govindaraju, D. R., \& Omholt, S. (2010). Phenomics: The next challenge. Nature Reviews Genetics, 11, 855-866. https://doi. org/10.1038/nrg2897

Jeong, S., Rokas, A., \& Carroll, S. B. (2006). Regulation of body pigmentation by the abdominal-B hox protein and its gain and loss in Drosophila evolution. Cell, 125, 1387-1399. https://doi.org/10.1016/j. cell.2006.04.043

Kopp, A., Duncan, I., \& Carroll, S. B. (2000). Genetic control and evolution of sexually dimorphic characters in Drosophilia. Nature, 408 , 553-559.

Kühl, H. S., \& Burghardt, T. (2013). Animal biometrics: Quantifying and detecting phenotypic appearance. Trends in Ecology \& Evolution, 28(7), 432-441.

Kuznetsova, A., Brockhoff, P. B., \& Christensen, R. H. B. (2017). ImerTest package: Tests in linear mixed effects models. Journal of Statistical Software, 82, 1-26.

Lande, R. (2014). Evolution of phenotypic plasticity and environmental tolerance of a labile quantitative character in a fluctuating environment. Journal of Evolutionary Biology, 27, 866-875. https://doi. org/10.1111/jeb.12360

Laughlin, D. C., \& Messier, J. (2015). Fitness of multidimensional phenotypes in dynamic adaptive landscapes. Trends in Ecology \& Evolution, 30(8), 487-496.

Lenth, R., Singman, H., Love, J., Buerkner, P., \& Herve, M. (2018). R package emmeans: Estimated marginal means.

Mallet, J., \& Joron, M. (1999). Evolution of diversity in warning color and mimicry: Polymorphisms, shifting balance, and speciation. Annual Review of Ecology and Systematics, 30, 201-233. https://doi. org/10.1146/annurev.ecolsys.30.1.201

Manenti, T., Sørensen, J. G., Moghadam, N. N., \& Loeschcke, V. (2016). Few genetic and environmental correlations between life history and stress resistance traits affect adaptation to fluctuating thermal regimes. Heredity (Edinb), 117, 149-154. https://doi.org/10.1038/ hdy.2016.34

Marquez, E. J., \& Knowles, L. L. (2007). Correlated evolution of multivariate traits: Detecting co-divergence across multiple dimensions. Journal of Evolutionary Biology, 20, 2334-2348. https://doi. org/10.1111/j.1420-9101.2007.01415.x

Massey, J. H., Chung, D., Siwanowicz, I., Stern, D. L., \& Wittkopp, P. J. (2019). The yellow gene influences drosophila male mating success through sex comb melanization. Elife, 8, e49388. https://doi. org/10.7554/eLife.49388

Massey, J. H., \& Wittkopp, P. J. (2016). The genetic basis of pigmentation differences within and between Drosophila species. Current Topics in Developmental Biology, 119, 27-61.

Mateus, A. R. A., Marques-Pita, M., Oostra, V., Lafuente, E., Brakefield, P. M., Zwaan, B. J., \& Beldade, P. (2014). Adaptive developmental 
plasticity: Compartmentalized responses to environmental cues and to corresponding internal signals provide phenotypic flexibility. BMC Biology, 12, 97. https://doi.org/10.1186/s12915-014-0097-x

Matute, D. R., \& Harris, A. (2013). The influence of abdominal pigmentation on desiccation and ultraviolet resistance in two species of Drosophila. Evolution (N. Y.), 67, 2451-2460.

Mckinnon, J. S., \& Pierotti, M. E. R. (2010). Colour polymorphism and correlated characters: Genetic mechanisms and evolution. Molecular Ecology, 19, 5101-5125. https://doi.org/10.1111/j.1365-294X.2010. 04846.x

Miyagi, R., Akiyama, N., Osada, N., \& Takahashi, A. (2015). Complex patterns of cis-regulatory polymorphisms in ebony underlie standing pigmentation variation in Drosophila melanogaster. Molecular Ecology, 24, 5829-5841.

Monteiro, A. (2015). Origin, development, and evolution of butterfly eyespots. Annual Review of Entomology, 60, 253-271.

Monteiro, A., Tong, X., Bear, A., Liew, S. F., Bhardwaj, S., Wasik, B. R., Dinwiddie, A., Bastianelli, C., Cheong, W. F., Wenk, M. R., Cao, H., \& Prudic, K. L. (2015). Differential expression of Ecdysone receptor leads to variation in phenotypic plasticity across serial homologs. PLoS Genetics, 11, e1005529. https://doi.org/10.1371/journ al.pgen.1005529

Nadeau, N. J. (2016). Genes controlling mimetic colour pattern variation in butterflies. Current Opinion in Insect Science, 17, 24-31. https://doi. org/10.1016/j.cois.2016.05.013

Nijhout, H. F. (2001). Elements of butterfly wing patterns. Journal of Experimental Zoology, 291, 213-225. https://doi.org/10.1002/ jez.1099

Nijhout, H. F. (2010). Molecular and physiological basis of colour pattern formation. In Advances in insect physiology (pp. 219-265). Academic Press.

Norry, F. M., \& Loeschcke, V. (2002). Temperature-induced shifts in associations of longevity with body size in Drosophila melanogaster. Evolution (N. Y.), 56, 299-306. https://doi.org/10.1111/j.0014-3820. 2002.tb01340.x

Orteu, A., \& Jiggins, C. D. (2020). The genomics of coloration provides insights into adaptive evolution. Nature Reviews Genetics, 21(8), 461-475.

Parkash, R., Lambhod, C., \& Singh, D. (2014). Thermal developmental plasticity affects body size and water conservation of Drosophila nepalensis from the Western Himalayas. Bulletin of Entomological Research, 104, 504-516.

Parkash, R., Rajpurohit, S., \& Ramniwas, S. (2008). Changes in body melanisation and desiccation resistance in highland vs. lowland populations of D. melanogaster. Journal of Insect Physiology, 54, 1050-1056. https://doi.org/10.1016/j.jinsphys.2008.04.008

Parkash, R., Singh, S., \& Ramniwas, S. (2009). Seasonal changes in humidity level in the tropics impact body color polymorphism and desiccation resistance in Drosophila jambulina-Evidence for melanismdesiccation hypothesis. Journal of Insect Physiology, 55(4), 358-368. https://doi.org/10.1016/j.jinsphys.2009.01.008

Pool, J. E., \& Aquadro, C. F. (2007). The genetic basis of adaptive pigmentation variation in Drosophila melanogaster. Molecular Ecology, 16, 2844-2851. https://doi.org/10.1111/j.1365-294X.2007.03324.x

R Core Team (2019). R: A language and environment for statistical computing.

Rajpurohit, S., \& Gibbs, A. G. (2012). Selection for abdominal tergite pigmentation and correlated responses in the trident: A case study in Drosophila melanogaster. Biological Journal of the Linnean Society, 106, 287-294. https://doi.org/10.1111/j.1095-8312.2012.01870.x

Rajpurohit, S., Parkash, R., \& Ramniwas, S. (2008). Body melanization and its adaptive role in thermoregulation and tolerance against desiccating conditions in drosophilids. Entomological Research, 38, 49-60. https://doi.org/10.1111/j.1748-5967.2008.00129.x
Reichstein, T., Von Euw, J., Parsons, J. A., \& Rothschild, M. (1968). Heart poisons in the monarch butterfly. Science, 161(3844), 861-866.

Ryan, C. G., Clayton, E., Griffin, W. L., Sie, S. H., \& Cousens, D. R. (1988). SNIP, a statistics-sensitive background treatment for the quantitative analysis of PIXE spectra in geoscience applications. Nuclear Instruments and Methods in Physics Research Section B, 34, 396-402.

Saleh Ziabari, O., \& Shingleton, A. W. (2017). Quantifying abdominal pigmentation in Drosophila melanogaster. Journal of Visualized Experiments: JOVE, 124(55732). https://doi.org/10.3791/55732

Schlichting, C., \& Pigliucci, M. (1998). Phenotypic evolution: A reaction norm perspective. Sinauer.

Shakhmantsir, I., Massad, N. L., \& Kennell, J. A. (2014). Regulation of cuticle pigmentation in drosophila by the nutrient sensing insulin and TOR signaling pathways. Developmental Dynamics, 243, 393-401.

Shearer, P. W., West, J. D., Walton, V. M., Brown, P. H., Svetec, N., \& Chiu, J. C. (2016). Seasonal cues induce phenotypic plasticity of Drosophila suzukii to enhance winter survival. BMC Ecology, 16, 11. https://doi. org/10.1186/s12898-016-0070-3

Shirai, L. T., Saenko, S. V., Keller, R. A., Jeronimo, M. A., Brakefield, P. M., Descimon, H., Wahlberg, N., \& Beldade, P. (2012). Evolutionary history of the recruitment of conserved developmental genes in association to the formation and diversification of a novel trait. BMC Evolutionary Biology, 12, 21. https://doi.org/10.1186/1471-2148-12-21

Sibilia, C. D., Brosko, K. A., Hickling, C. J., Thompson, L. M., Grayson, K. L., \& Olson, J. R. (2018). Thermal physiology and developmental plasticity of pigmentation in the Harlequin Bug (Hemiptera: Pentatomidae). Journal of Insect Science, 18, 4. https://doi.org/10.1093/jisesa/iey066

Solensky, M. J., \& Larkin, E. (2003). Temperature-induced variation in larval coloration in Danaus plexippus (Lepidoptera: Nymphalidae). Annals of the Entomological Society of America, 96, 211-216.

Taiyun, W., \& Viliam, S. (2017). R package "corrplot": Visualization of a correlation matrix.

Takahashi, A. (2013). Pigmentation and behavior: Potential association through pleiotropic genes in Drosophila. Genes \& Genetic Systems, 88, 165-174.

Telonis-Scott, M., Hoffmann, A. A., \& Sgrò, C. M. (2011). The molecular genetics of clinal variation: A case study of ebony and thoracic trident pigmentation in Drosophila melanogaster from eastern Australia. Molecular Ecology, 20, 2100-2110. https://doi. org/10.1111/j.1365-294X.2011.05089.x

True, J. R. (2003). Insect melanism: The molecules matter. Trends in Ecology \& Evolution, 18, 640-647. https://doi.org/10.1016/j. tree.2003.09.006

True, J. R., Edwards, K. A., Yamamoto, D., \& Carroll, S. B. (1999). Drosophila wing melanin patterns form by vein-dependent elaboration of enzymatic prepatterns. Current Biology, 9, 1382-1391. https:// doi.org/10.1016/S0960-9822(00)80083-4

Trullas, S. C., van Wyk, J. H., \& Spotila, J. R. (2007). Thermal melanism in ectotherms. Journal of Thermal Biology, 32, 235-245. https://doi. org/10.1016/j.jtherbio.2007.01.013

van Bergen, E., \& Beldade, P. (2019). Seasonal plasticity in anti-predatory strategies: Matching of color and color preference for effective crypsis. Evolution Letters, 3(3), 313-320. https://doi.org/10.1002/ evl3.113

van't Hof, A. E., Edmonds, N., Dalikova, M., Marec, F., \& Saccheri, I. J. (2011). Industrial melanism in British peppered moths has a singular and recent mutational origin. Science, 332, 958-960. https://doi. org/10.1126/science.1203043

Vargas-Lowman, A., Armisen, D., Burguez Floriano, C. F., da Rocha Silva Cordeiro, I., Viala, S., Bouchet, M., Bernard, M., Le Bouquin, A., Santos, M. E., Berlioz-Barbier, A., Salvador, A., Figueiredo Moreira, F. F., Bonneton, F., \& Khila, A. (2019). Cooption of the pteridine biosynthesis pathway underlies the diversification of embryonic colors in water striders. Proceedings of the National Academy of Sciences 
of the United States of America, 116, 19046-19054. https://doi. org/10.1073/pnas.1908316116

Vrieling, H., Duhl, D. M. J., Millar, S. E., Miller, K. A., \& Barsh, G. S. (1994). Differences in dorsal and ventral pigmentation result from regional expression of the mouse agouti gene. Proceedings of the National Academy of Sciences of the United States of America, 91, 5667-5671. https://doi.org/10.1073/pnas.91.12.5667

Werner, T., Koshikawa, S., Williams, T. M., \& Carroll, S. B. (2010). Generation of a novel wing colour pattern by the Wingless morphogen. Nature, 464, 1143-1148. https://doi.org/10.1038/nature08896

Wickham, H. (2009). Ggplot2: Elegant graphics for data analysis. Springer.

Wickham, H., \& Henry, L. (2020). tidyr: Tidy Messy Data.

Wiernasz, D. C. (1995). Male choice on the basis of female melanin pattern in Pieris butterflies. Animal Behavior, 49, 45-51. https://doi. org/10.1016/0003-3472(95)80152-9

Williams, T. M., Selegue, J. E., Werner, T., Gompel, N., Kopp, A., \& Carroll, S. B. (2008). The regulation and evolution of a genetic switch controlling sexually dimorphic traits in Drosophila. Cell, 134, 610-623. https://doi.org/10.1016/j.cell.2008.06.052

Wittkopp, P. J., \& Beldade, P. (2009). Development and evolution of insect pigmentation: Genetic mechanisms and the potential consequences of pleiotropy. Seminars in Cell \& Developmental Biology, 20, 65-71. https://doi.org/10.1016/j.semcdb.2008.10.002

Wittkopp, P. J., Carroll, S. B., \& Kopp, A. (2003). Evolution in black and white: Genetic control of pigment patterns in Drosophila. Trends in Genetics, 19, 495-504. https://doi.org/10.1016/S01689525(03)00194-X
Wittkopp, P. J., Smith-Winberry, G., Arnold, L. L., Thompson, E. M., Cooley, A. M., Yuan, D. C., Song, Q., \& McAllister, B. F. (2011). Local adaptation for body color in Drosophila americana. Heredity (Edinb), 106, 592-602. https://doi.org/10.1038/hdy.2010.90

Wittkopp, P. J., Vaccaro, K., \& Carroll, S. B. (2002). Evolution of yellow gene regulation and pigmentation in Drosophila. Current Biology, 12, 1547-1556. https://doi.org/10.1016/S0960-9822(02)01113-2

Zhang, L., Martin, A., Perry, M. W., van der Burg, K. R. L., Matsuoka, Y., Monteiro, A., \& Reed, R. D. (2017). Genetic basis of melanin pigmentation in butterfly wings. Genetics, 205, 1537-1550. https://doi. org/10.1534/genetics.116.196451

\section{SUPPORTING INFORMATION}

Additional supporting information may be found online in the Supporting Information section.

How to cite this article: Lafuente E, Alves F, King JG, Peralta CM, Beldade P. Many ways to make darker flies: Intra- and interspecific variation in Drosophila body pigmentation components. Ecol Evol. 2021;11:8136-8155. https://doi.org/10.1002/ece3.7646 

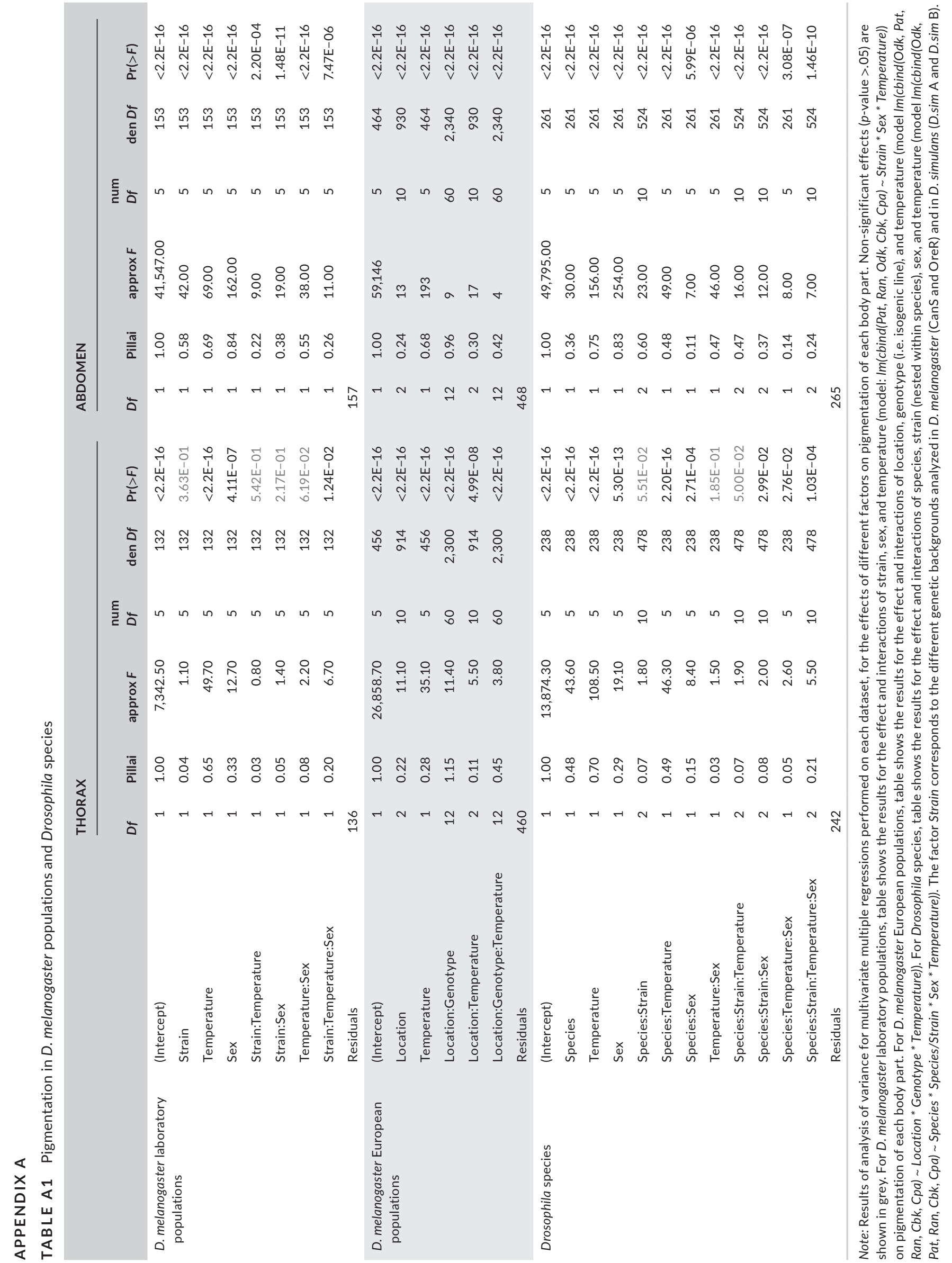


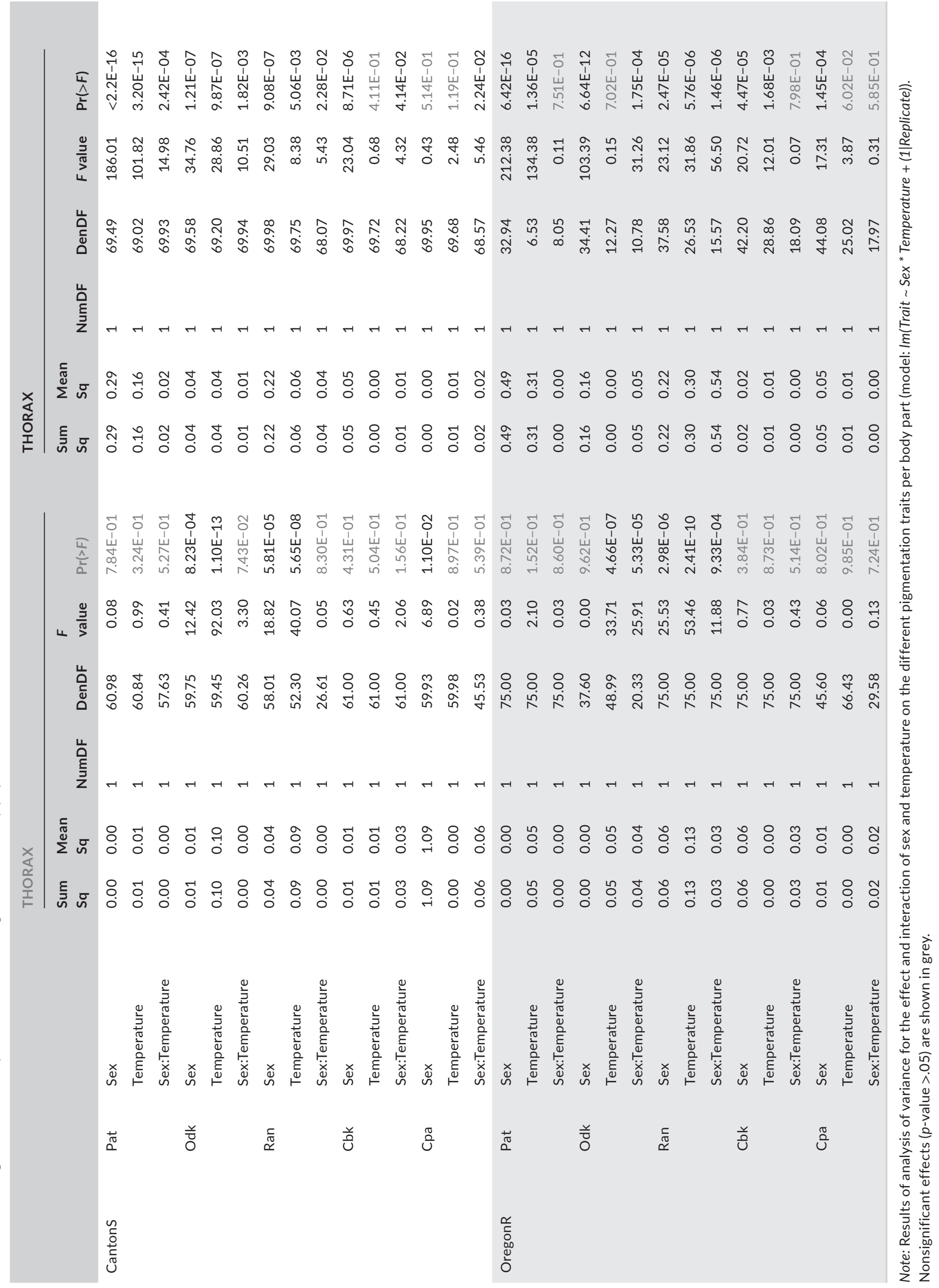


TABLE A3 Windows of sensitivity for pigmentation plasticity in $D$. melanogaster

\begin{tabular}{|c|c|c|c|c|c|c|}
\hline & & $D f$ & Sum Sq & Mean Sq & $F$ value & $\operatorname{Pr}(>F)$ \\
\hline \multirow[t]{4}{*}{ Pat } & Strain & 1 & 0.08 & 0.08 & 17.32 & 4.09E-05 \\
\hline & Regime & 8 & 1.07 & 0.13 & 28.65 & $<2.2 \mathrm{e}-16$ \\
\hline & Strain:Regime & 8 & 0.17 & 0.02 & 4.42 & $4.40 \mathrm{E}-05$ \\
\hline & Residuals & 312 & 1.46 & 0.00 & & \\
\hline \multirow[t]{4}{*}{ Odk } & Strain & 1 & 0.00 & 0.00 & 1.02 & 3.13E-01 \\
\hline & Regime & 8 & 1.25 & 0.16 & 40.31 & $<2.2 \mathrm{e}-16$ \\
\hline & Strain:Regime & 8 & 0.22 & 0.03 & 6.96 & $1.63 \mathrm{E}-08$ \\
\hline & Residuals & 347 & 1.35 & 0.00 & & \\
\hline \multirow[t]{4}{*}{ Ran } & Strain & 1 & 1.73 & 1.73 & 101.40 & $<2.2 \mathrm{e}-16$ \\
\hline & Regime & 8 & 4.94 & 0.62 & 36.20 & $<2.2 \mathrm{e}-16$ \\
\hline & Strain:Regime & 8 & 0.45 & 0.06 & 3.33 & $1.11 \mathrm{E}-03$ \\
\hline & Residuals & 347 & 5.92 & 0.02 & & \\
\hline \multirow[t]{4}{*}{ Cbk } & Strain & 1 & 0.01 & 0.01 & 3.93 & $4.82 \mathrm{E}-02$ \\
\hline & Regime & 8 & 0.20 & 0.02 & 17.24 & $<2.2 \mathrm{e}-16$ \\
\hline & Strain:Regime & 8 & 0.10 & 0.01 & 8.98 & $3.32 \mathrm{E}-11$ \\
\hline & Residuals & 347 & 0.49 & 0.00 & & \\
\hline \multirow[t]{4}{*}{ Сра } & Strain & 1 & 0.09 & 0.09 & 26.16 & $5.22 \mathrm{E}-07$ \\
\hline & Regime & 8 & 0.63 & 0.08 & 22.36 & $<2.2 \mathrm{e}-16$ \\
\hline & Strain:Regime & 8 & 0.17 & 0.02 & 6.15 & $2.00 \mathrm{E}-07$ \\
\hline & Residuals & 347 & 1.23 & 0.00 & & \\
\hline
\end{tabular}

Note: Results of analysis of variance for the effect and interaction of strain and thermal regime on the different pigmentation traits per body part (model: Im(Trait Strain*Regime)). 


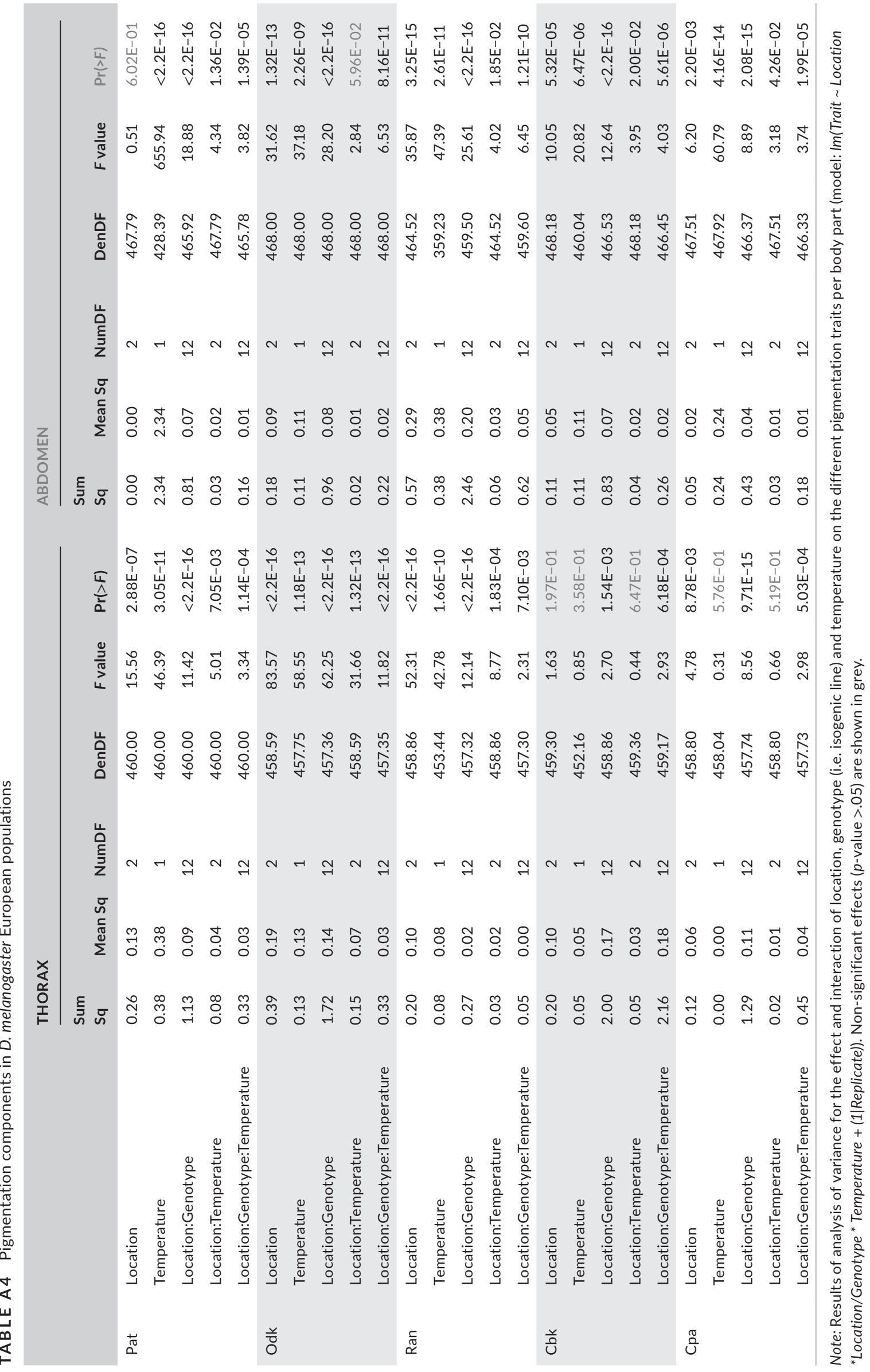




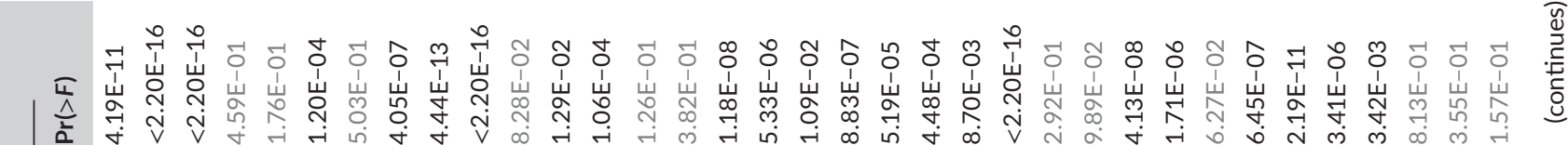

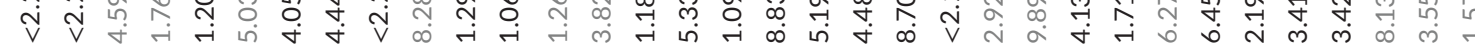

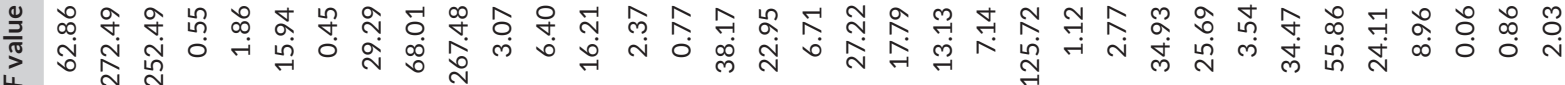

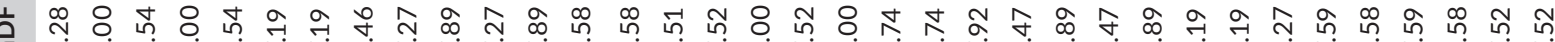

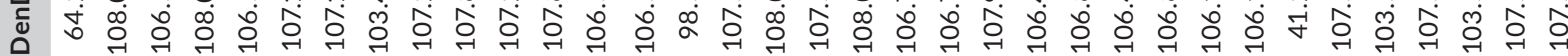

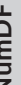

z

ธ

崖

至

m

โี 핏

党

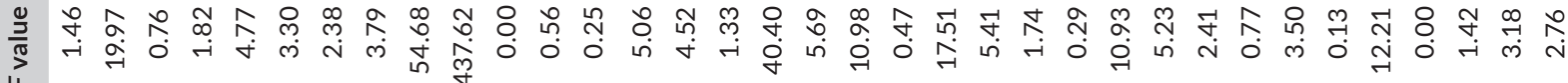

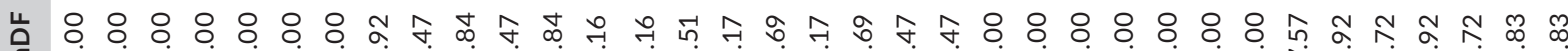

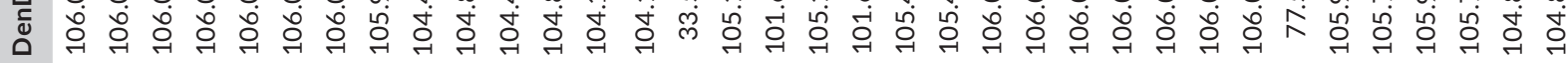

虫

党

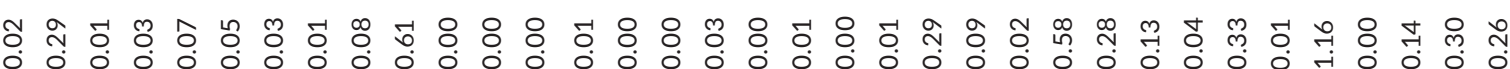




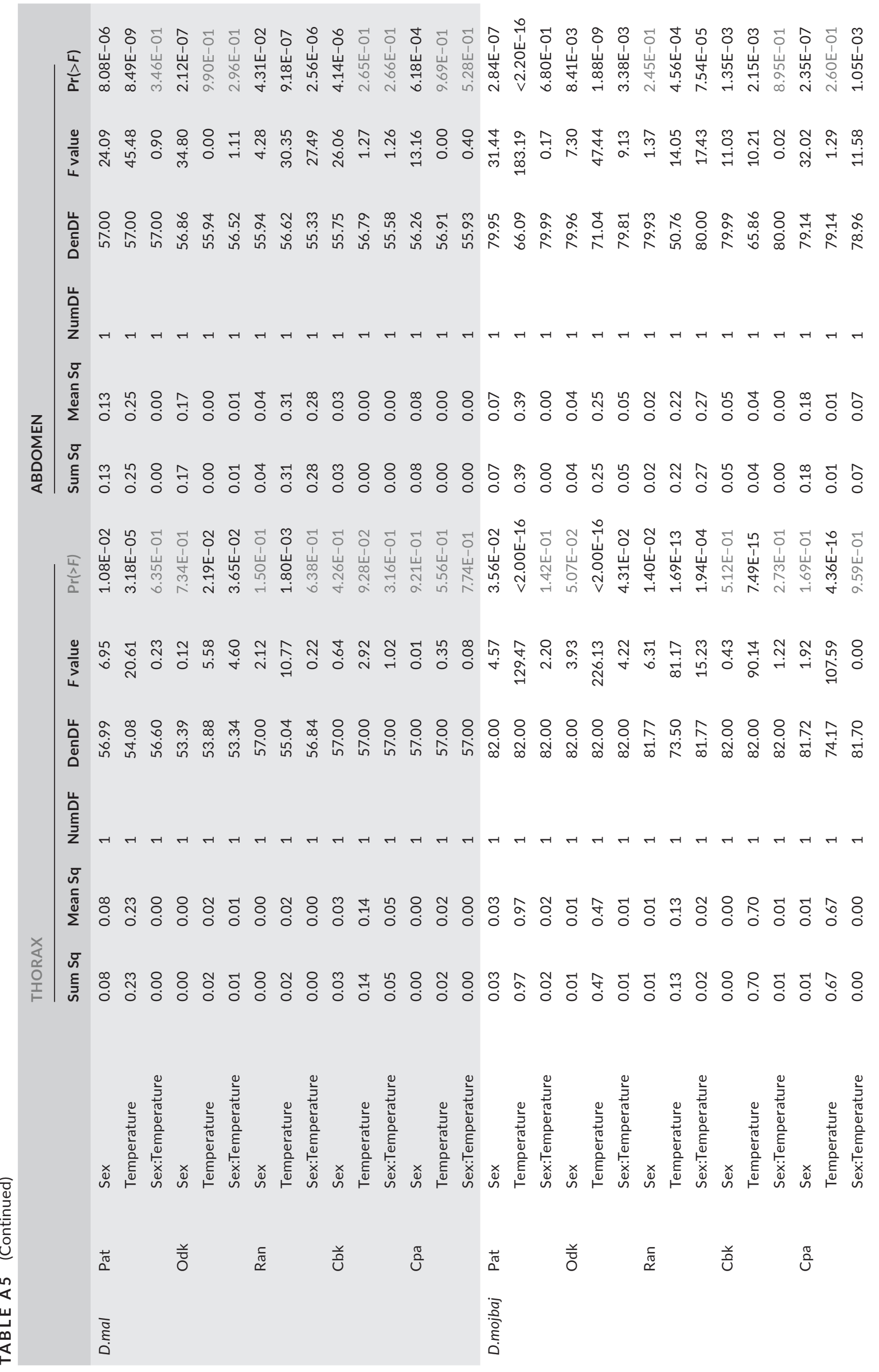




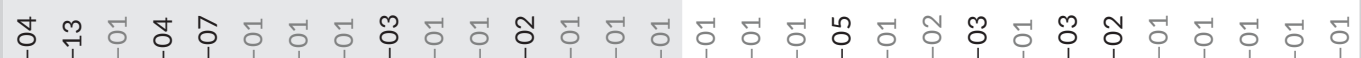

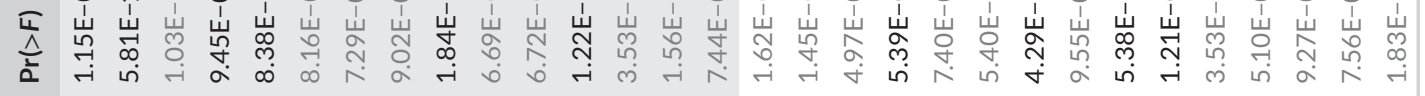

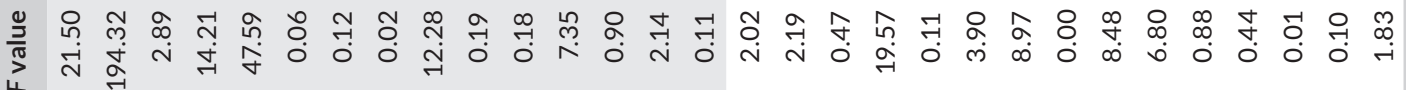

य वั๊

敢 品

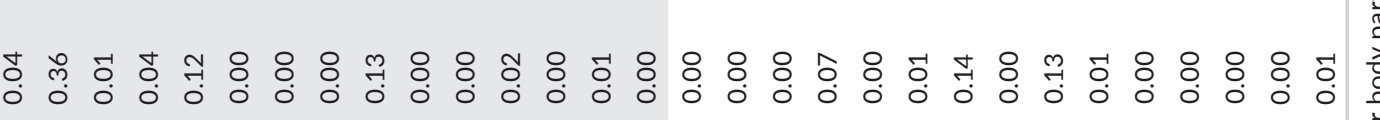
-

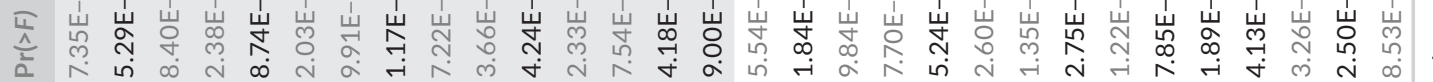

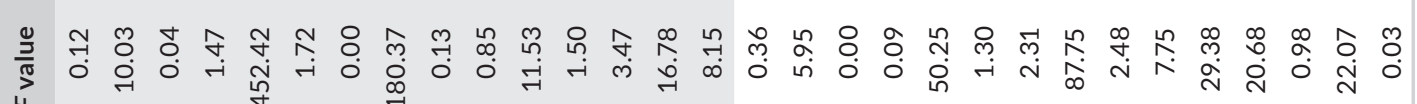

แ ด 